المنهج الاستدلالي العقلي عند الإمام عبد القاهر البغدادي

المنهج الاستدلالي العقلي عند الإمام عبد القاهر البغدادي (ت 9 ؟ هـ) في

كتابه(أصول الاين)

أ.م.د. هادي عبيد حسن

السيا : عصام محمود جاسم المحمدي

جامعة الانبار / كلية العلوم الاسلاميه / قسم العقيدة والدعوه والفكر جمري المعري

\title{
الخلاصة
}

بعـد هـذه الجولـة الفكريـة في منهجيـة الإمـام البغـدادي في مسـالة الاسـتـلال العقلـي مـن كتابه "أصول الدين" نبيّن أبرز تلكم النتائج:

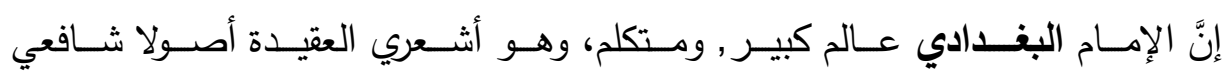

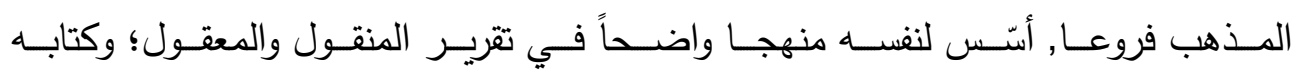

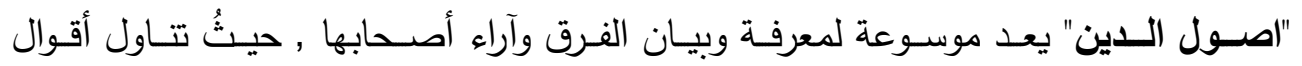

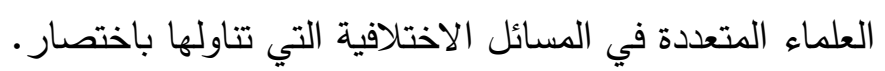

وكـان اسـلوبه واضـحا ودقيقـا في عـرض المسـائل العقديـة , وهـو مـن المراجـع المهـــة

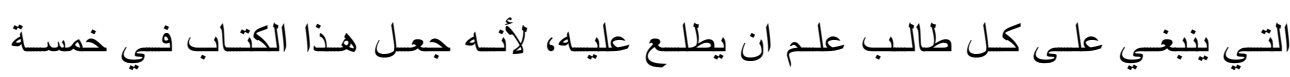

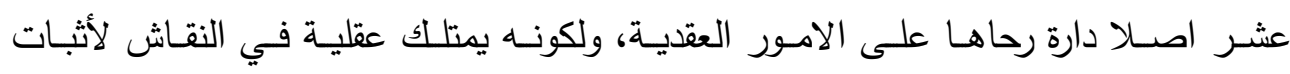

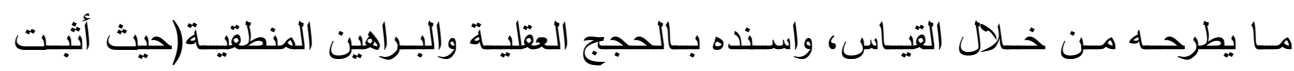

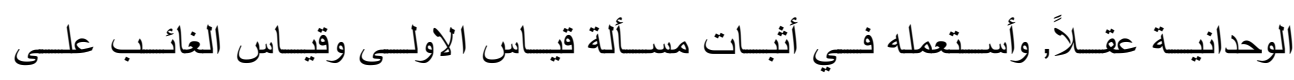
الشاهد, وجاء بالسبر والتقسيم, في مسألة الرؤية ونفي الحد عن الصانع ) . 
أ.م.د. هادي عبيد حسن /أ . عصام محمود جاسم المحمدي

\section{مقِّمة مة}

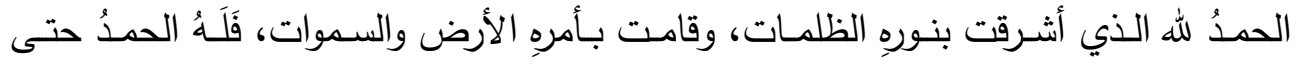

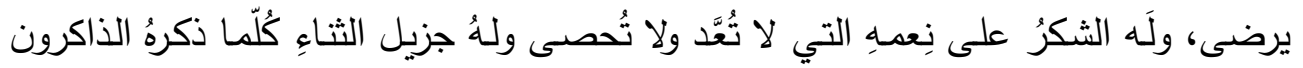

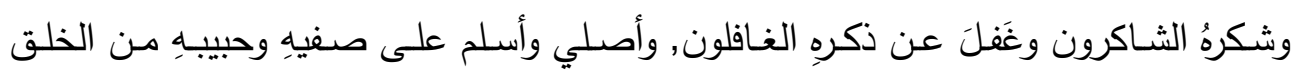

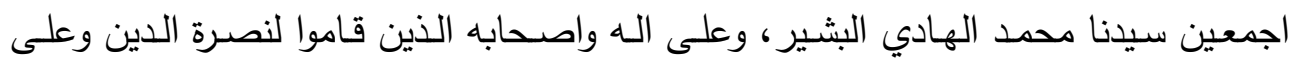
تابعيهم بإحسان إلى يوم الدين.

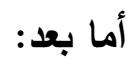

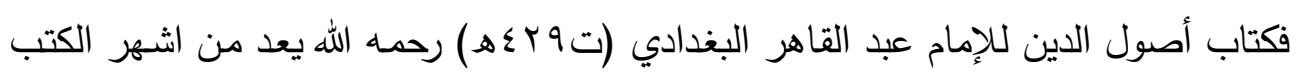

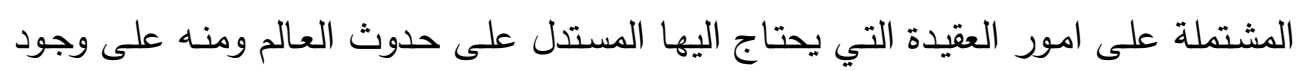

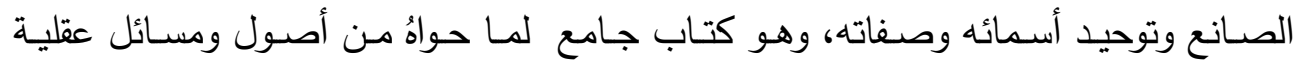

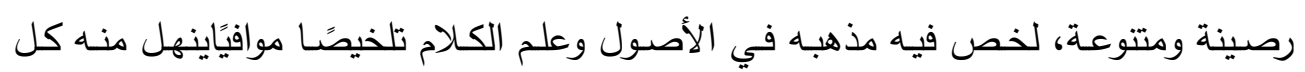

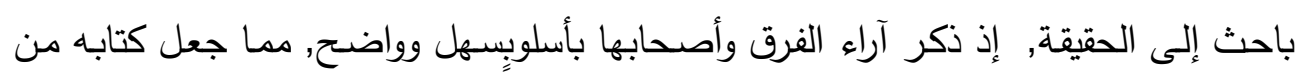

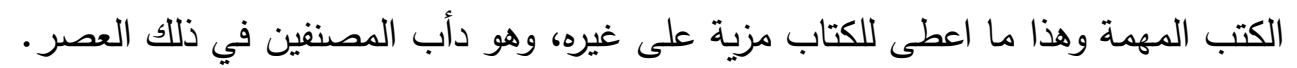

\section{أهمية الموضوع, وسبب اختياري لهُ:}

لا يخفى على من أنتسب إلى دائرة البحث العلمي أنه لا بد للموضوع من أهمية

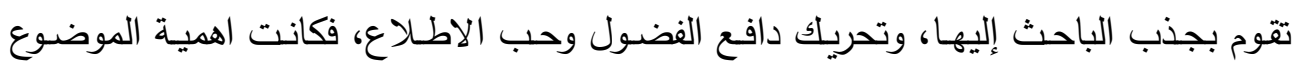

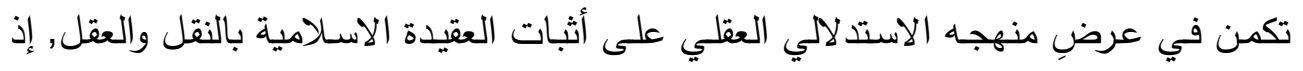

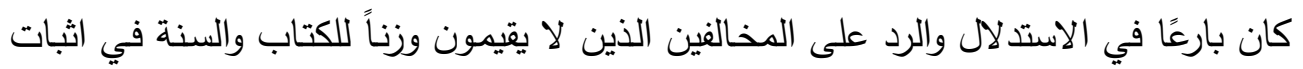

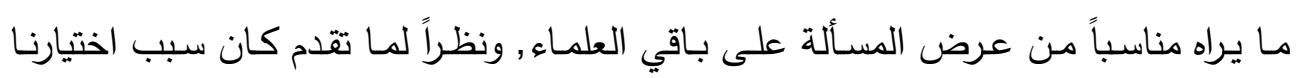
الموضوع وامـا عن موضوع بحثنالمسمى ب(المنهج الاستدلالي العقلي عند الإمسام عبد

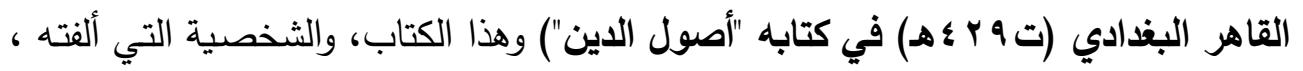

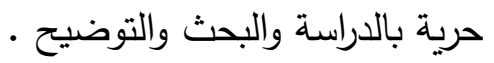
اما خطة البحث، فقد اقتضت طبيعة تقسيمه الى مقدمةواربعة مطالب وخاتمة، وكما يأتي: مجلة بحوث كلية الآداب 
"المام المنهج الاستدلالي العقلي عند الإمام عبد القاهر البذادي

المطلب الأول: حياة الإمام البغداديوالتعريف بالمنهج والاستدل لال والعقل.

المطلب الثاني:منهجه في اثبات الوحدانية.

المطلب الثالث: منهجه في قياس الغائب على الثاهد؛ وقياس الأولى الثية.

المطلب الرابع:منهجه في السبر والتقسيم.

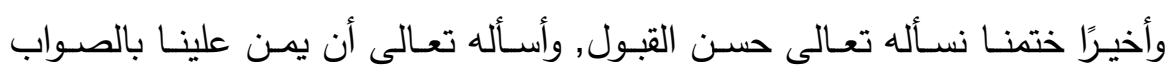

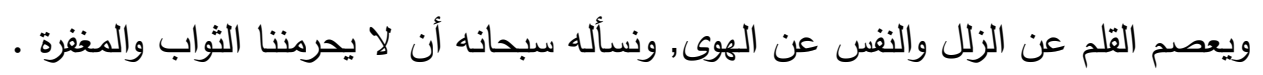

الباحثان 


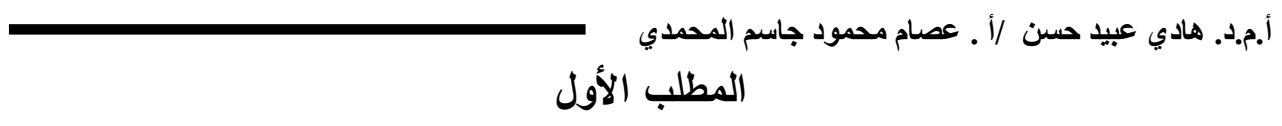

\section{حياة الإمام البذادي والتعريف بالمنهج والاستدلال والعقل

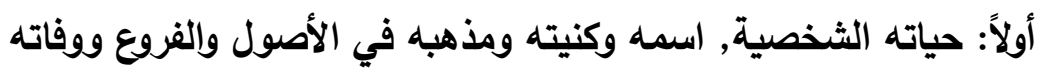

- اسمهة: عبدالقاهر بن طاهر بن محمد بن عبدالله التميمي البغدادي(') -

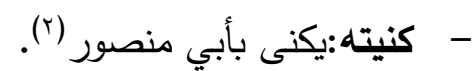

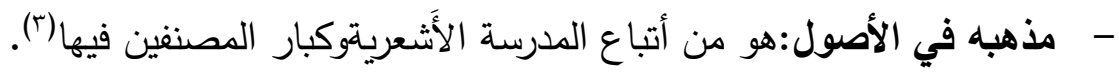

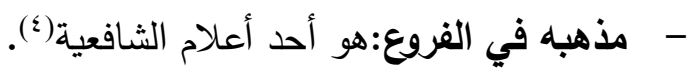

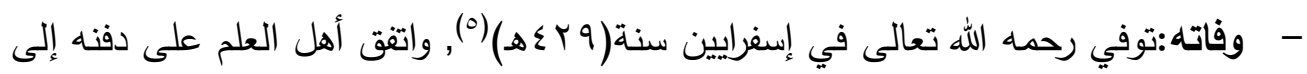

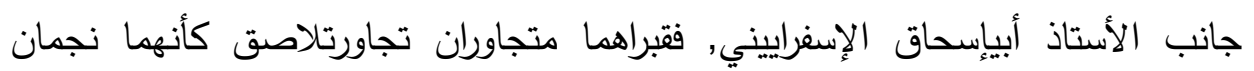

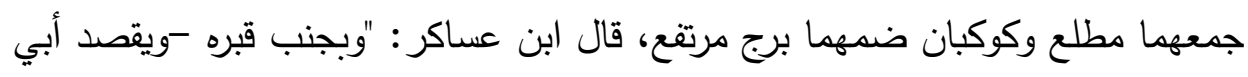

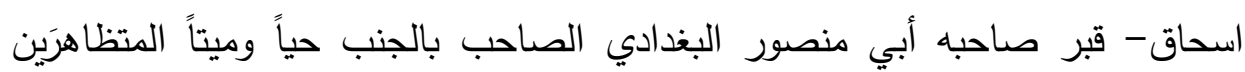
لنصرة الدين بالحجج والبراهين"(7).

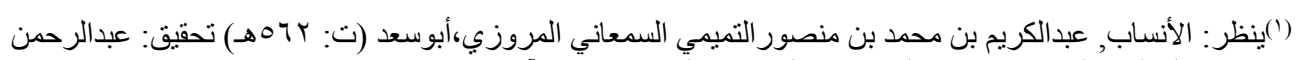

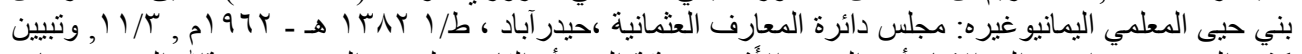

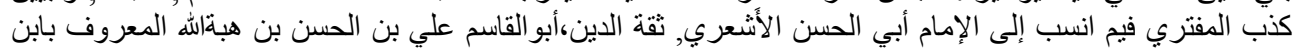

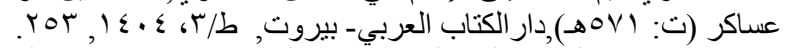

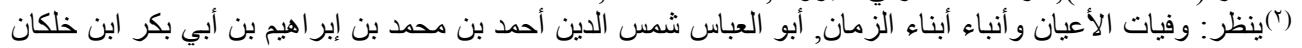

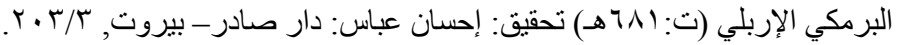

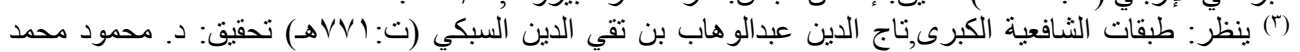

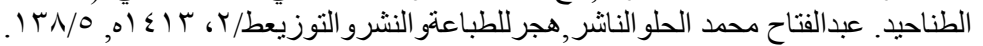

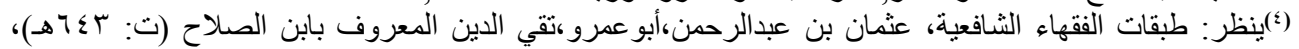

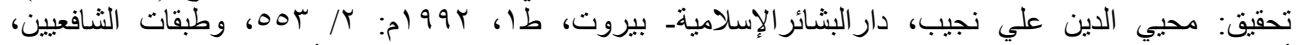

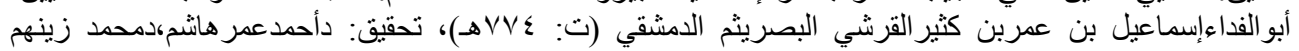

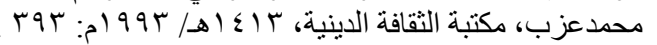

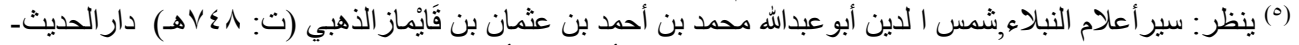

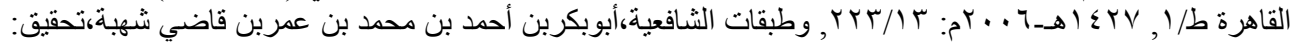

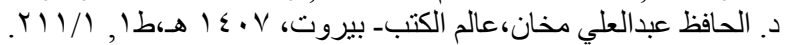

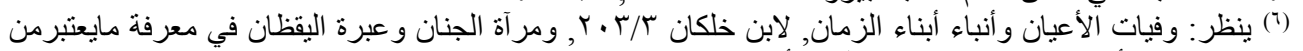

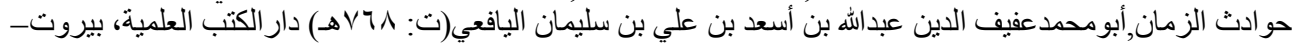

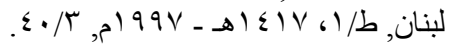

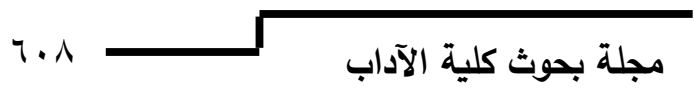


المنهج الاستدلالي العقلي عند الإمام عبد القاهر البغدادي

ثانياً: المنهج لغة واصطلاحاً.

وجب علينا قبل الدخول في مفردات المنهجية أن نبين معنى كلمة منهج: أن كلمة

منهج تدل على الطريق الواضح المستقيم.

ولذلك جاءت فياللغة:المنهج والمنهاج، وجمعه مناهج، معناه الطريق الواضتح, نهج

لي الأمـر أوضـحه فهو مستقيم المنهاج(V), واستعمل في القرآن الكريم بهذا المعنى، قـال

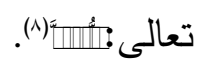

والمنهج اصطلاحا له تعريفات مختلفة نذكر منها: "فن التنظيم الصحيح لسلسلة الافكار العديدة إما من جهة الكثف عن الحقيقة حيث نكون بها جاهلين, وإما من أجل البرهنة عليها للآخرين حيث نكون بها عارفين"(9),وبمدلول أوسع ومفهوم أشمل بتنظيم مراحل عديدة "تبدأ بجمع المادة وطريقة اختيارها وتصنيفها وتبويبها تبويباً واضحاً في تسلسل

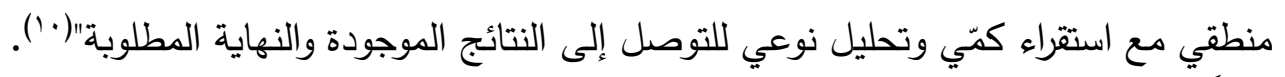

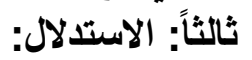

الاستدلال لغة:طلب الدليل(') الاسئل:

واصطلاحا: ذكرالدليل نصاً كان او إجماعاً أو قياساً أو غيره(rال').

وهو أيضا: تقرير الدليل لإثبات المدلول سواءً كان ذلك من الأثر، اي المؤثر أو لهاء

العكس، أو من أحد الأثرين إلى الآخر (r').

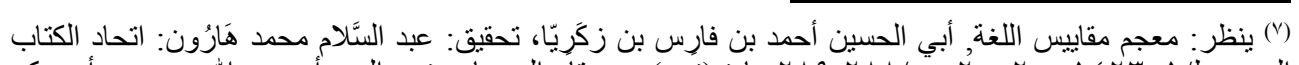

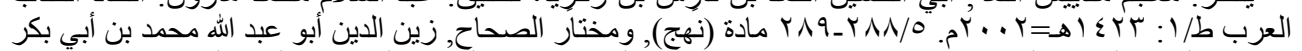

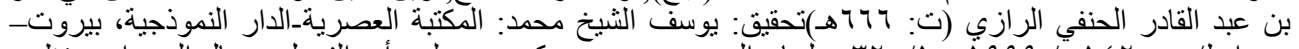

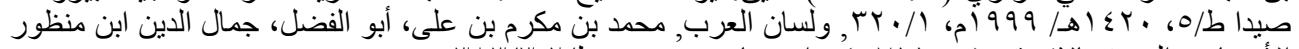

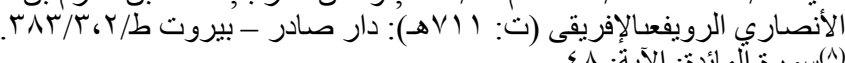

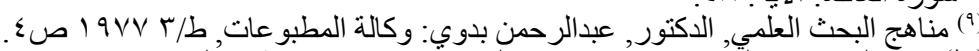

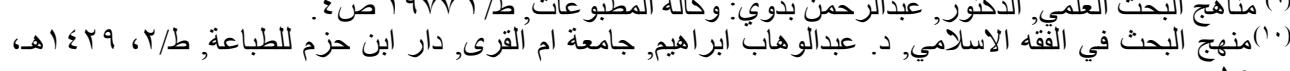

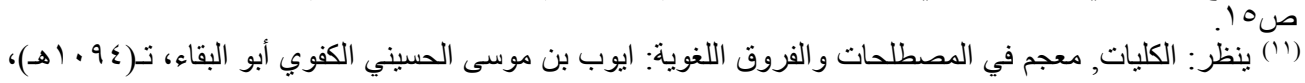

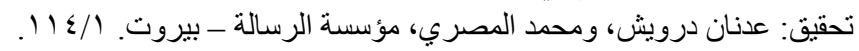

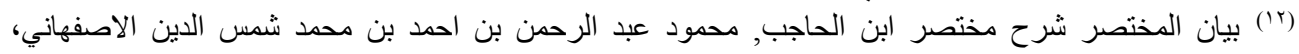

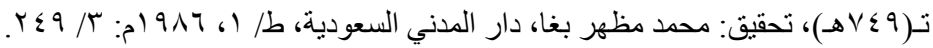

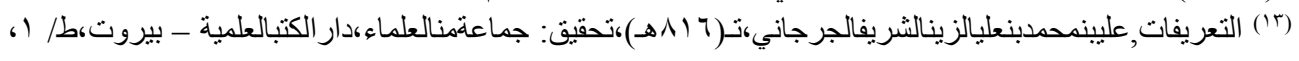
iv: 1914 
وإذا نظرنا نظرة فاحصة إلى كل موضوع لرأينا أنه يستند إلى دليل، وهذا الدليل إما

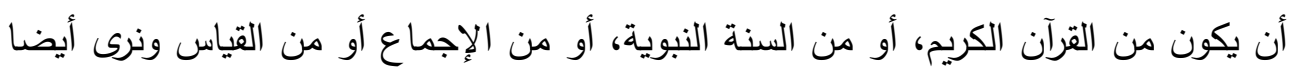

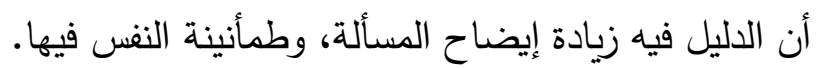
استدل الإمام البغدادي على إثبات العقائد بالنقل والعقل, فيثبت ما جاء بالنقل من أوصاف الباري جل جلاله, وأسمائه والاعتقاد برسله واليوم الآخر والملائكة والحساب

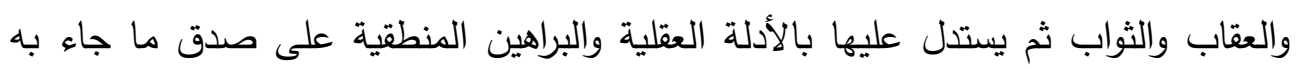
القران الكريم والسنة النبوية والاجماع والقياس بعد ما أوجب التصديق بها كما هي نقلاً.

واستعان في سبيل ذلك بقضايا فلسفية ومسائل عقلية خاض فيها الفلاسفة وسلكها المناطقة؛ وذلك لأنه تصدى للمعتزلة وفرقهم, وهؤلاء لا يقتنعون إلاّ بالأدلة المنطقية. والاستدلال عنده يكون بالأدلة العقلية والنقلية على وجه التعاضد, فالأدلة سواءاً أكانت عقلية أم نقلية يؤيد بعضها بعضاً, فهو يرى أَن النقل الثابت الصريح والعقل الصحيح

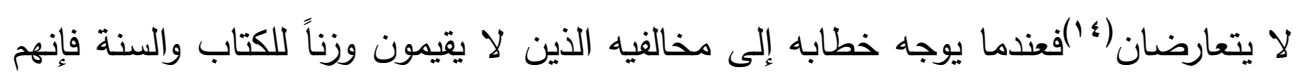
يقدمون الأَدلة العقلية على النقلية.

$$
\text { رابعاً: العقل }
$$

العقل لغة:نقيض الجهل يقالع قليعق لعقلاً إذاعرف ماكان يجهله قبل(ه(1). العقل اصطلاحاً: ذكر العلماء تعريفات عدة:منها

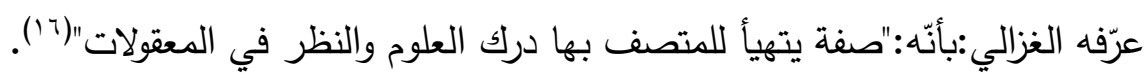

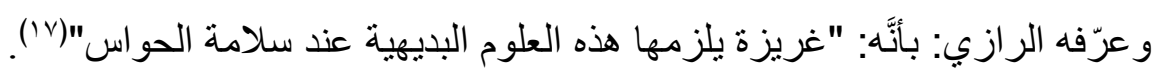

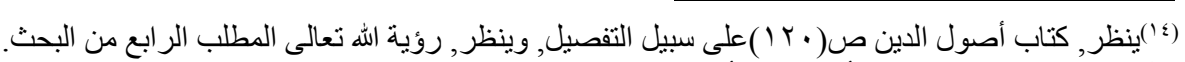

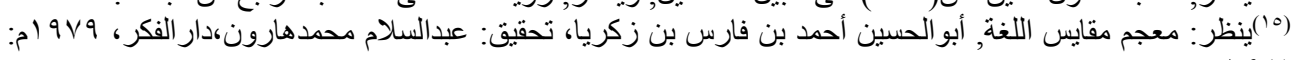

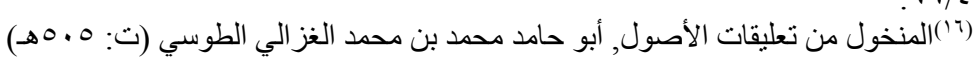

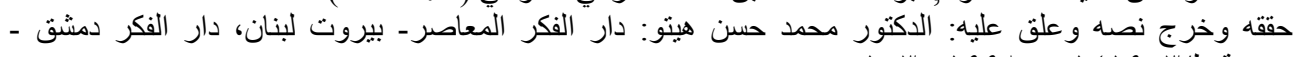

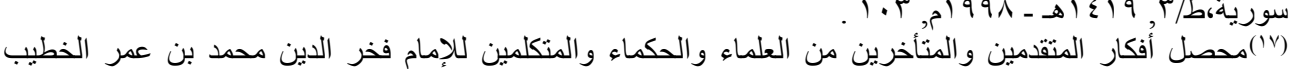

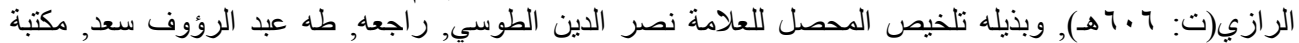

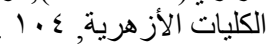


المنهج الاستدلالي العقلي عند الإمام عبد القاهر البغدادي

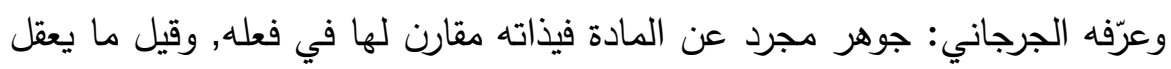
به حقائق الاشياء, والصحيح انه جوهر مجرد يدرك الفانياتب الوسائط والمحسوساتب

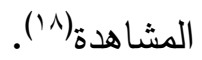
والمر اد بالعلوم البديهية: العلم: بوجوب الواجبات،واستحالة المستحيلات. لم يختلف الإمام البغدادي عمّن سبقه من المتكلمين في الرد على خصومده, وقد

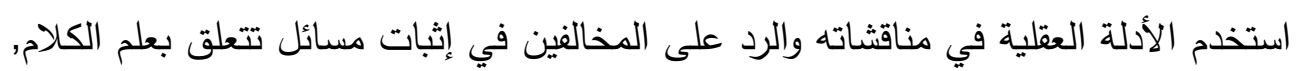

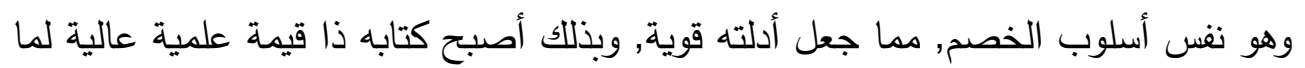

$$
\begin{aligned}
& \text { فيه من الأدلة العقلية والنقلية. } \\
& \text { المطلب الثاني } \\
& \text { منهجه في أثبات الوحدانية }
\end{aligned}
$$

ونتتاول بعض المسائل التي استخدمها الإمام البغدادي في استدلالاته العقلية:

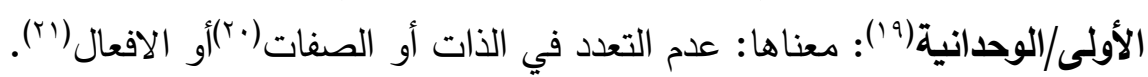

فالوحدانية في الذات تنفي (الكََّّ المتُصُّل) أي ليس مركب من أجزاء, وتتفي (الكَمَّم

المنفصل) أي هنالك أكثر من إله.

والوحدانية في الصفات تتفي (الكََّّ المتُصَّل) أي عدم تعددها من جنس واحد كقدرتين

فأكثر وعلمين فأكثر , وتتفي(الكََّّ المنفصل) الذي هو إثبات صفة لغيره تعالى تثبه صفته.

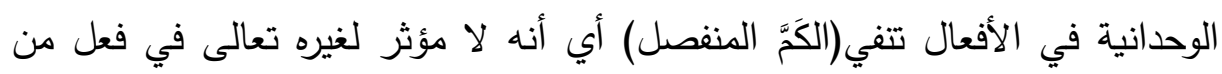

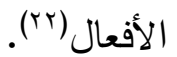

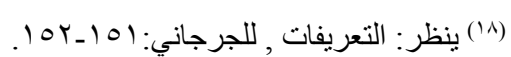

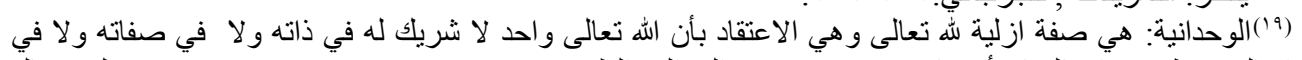

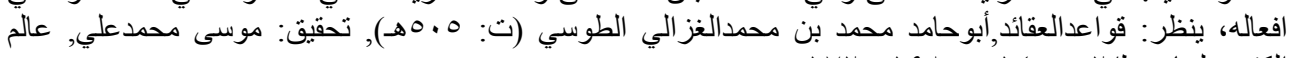

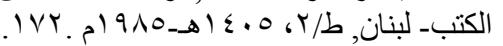

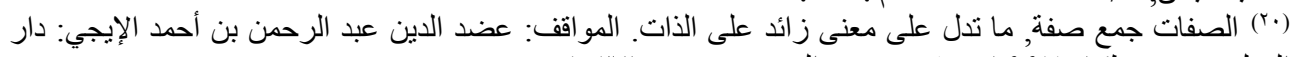

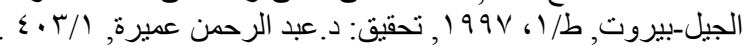

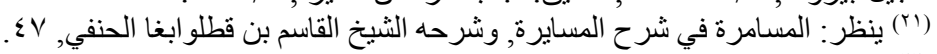

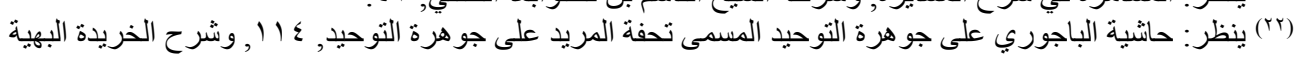

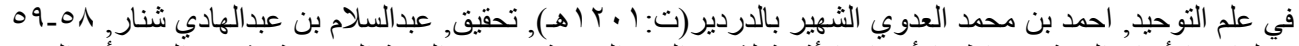

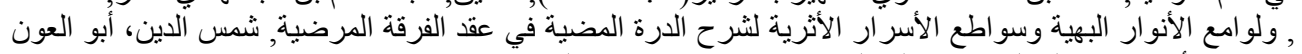

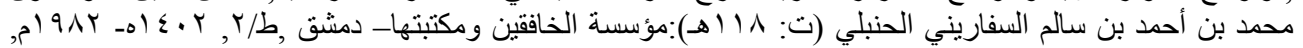




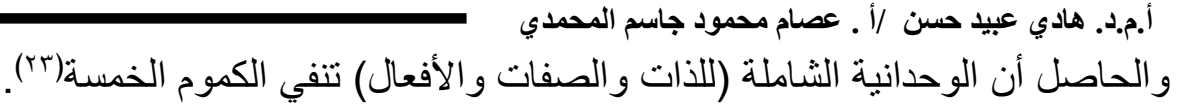

واستخدم الإمام البغدادي هذه الادلة لكنه لم يعرضها كما هو معهود الان, منها:

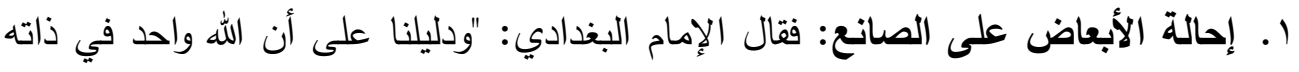
ليس بذي أجزاء وأبعاض, أنه قد صحّ أنه حيّ قادر عالم مريد, فلو كان ذا أجزاء وأبعاض لم يَخْلُ من أن يكون في كل جزء منه حياة وقدرة وعلم وإرادة, أو يكون هذه الصفات في بعض أجزائه, فإن كان في كل جزء منه مثل هذه الصفات كان كل جزي جنه منه حيّا قادراً عالماً مريداً بانغراده, ولو كان كذلك لصحَ وقوع الخلاف بين أعضائه حتى يريد

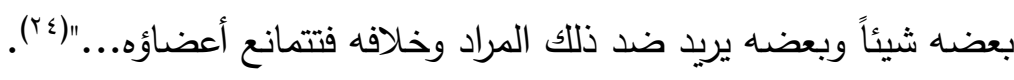
r. توحيد الصانع: يثبت الإمام البغدادي إن للعالم صانع واحد, وانه صانع الاجسام وهو

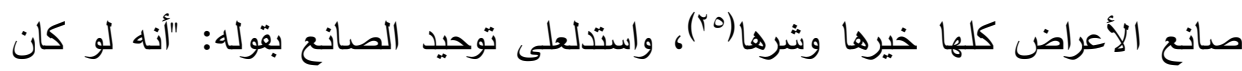

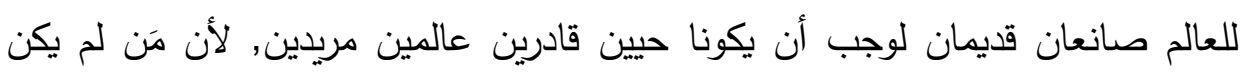

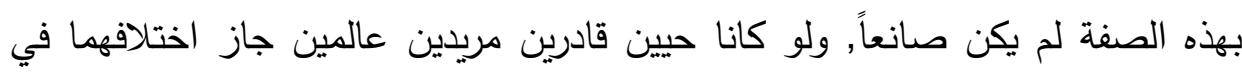
المراد, بان يريد احدهما حياة جسم ويريد الآخر موته, ولم يَخلُ حينئذ من أن يتم مرادهما معاً أو لا يتم مرادهما معاً أو يتم مراد أحدهما دون الآخر , ومحال تمام مرادهما لاستحالة كون الثيء حيَّا وميتاً في حالة واحدة وإن لم يتم مرادهما ظهر عجزهما, وإن تم مراد أحدهما دون الآخر ظهر عجز الذي لم يتم مراده والعاجز لا يكون إلهاً"(rآ.

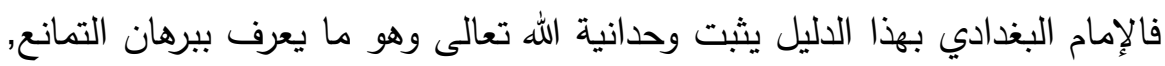
ودليل التمانع هو من أثهر البراهين العقلية في اثبات الوحدانية ونفي التعدد في الخالق, ويتألف هذا البرهان من مقدمتين اساسيتين: وجود الانسجام والوحدة والتناسق في العالم.

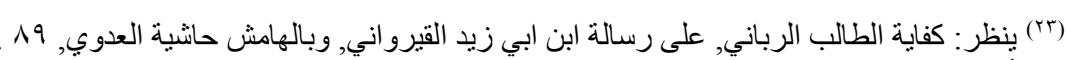

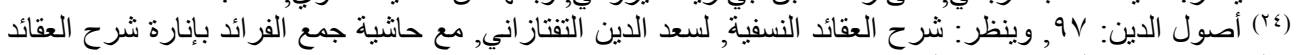

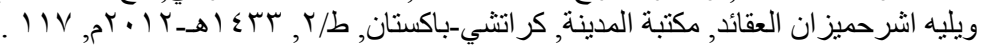
(ro)

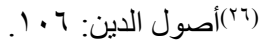


المنهج الاستدلالي العقلي عند الإمام عبد القاهر البغدادي

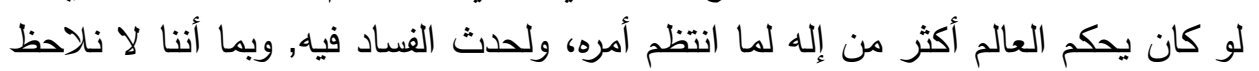

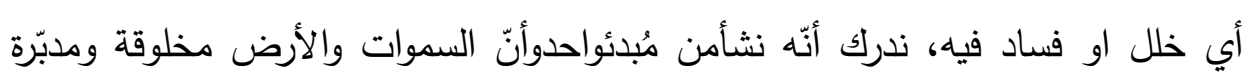

$$
\text { ومنظّمة من خالق واحد (rV). }
$$

وهو بذللك يتفق مع الإمام الباقلاني بهذا الدليل قائلاً:" وليس يجوز أن يكون صانع العالم

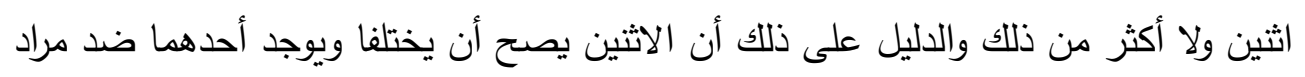
الآخر فلو اختلفا وأراد أحدهما إحياء جسم وأراد الآخر إماتته لوجب أن يلحقهما العجز أو أولين واحدا منهما لأنه محال أن يتم ما يريدان جميعا لتضاد مراديهما فوجب أن لا يتما أو يتم

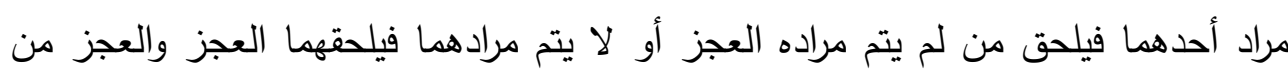

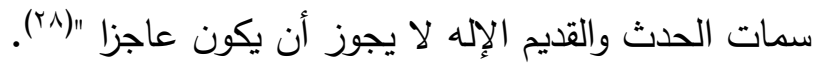
وجاء المتأخرون من الأثاعرة واستخدموا هذا الدليل ومنهم التفتازاني في اثبات وحدانية الله تعالى حيث قال:" لوتعدد الإله لكان بينهما التنازع والتغالب, وتميز صنع كل عن واعن صنع الآخر بحكم اللزوم العادي, فلم يحصل بين أجزاء العالم هذا الالتئام الذي باعتباره صار الكل بمنزلة شخص واحد, ويختل الانتظام الذي به بقاء الأنواع وترتب الآثار "(9؟).

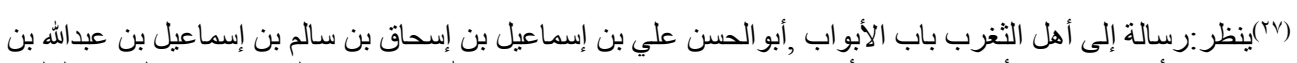

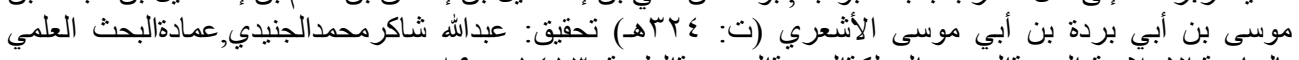

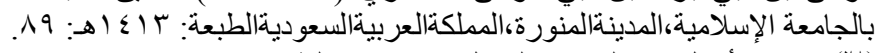

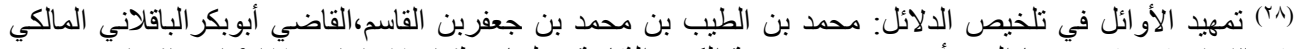

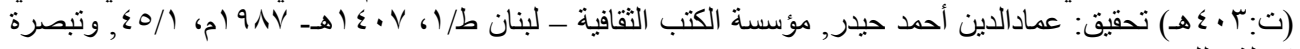

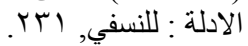
(ra) شرح الدقاصد: للتفتاز اني, ك/r/T. 

أ.م.د. هادي عبيا حسن /أ. عصام محمود جاسم المحمدي الثالث

منهجه في قياس الغائب على الثاهد؛ وقياس الاولى الملى الاولى: قياس الغائب على الثاهد:

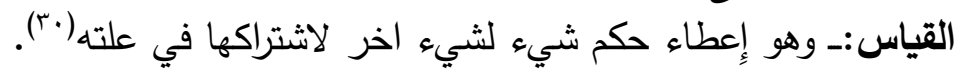

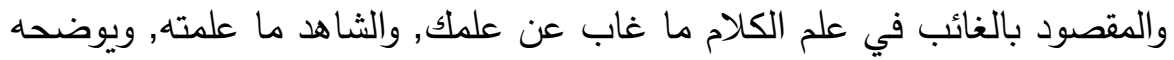

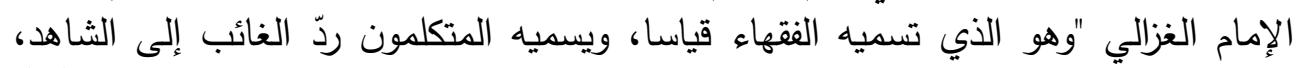

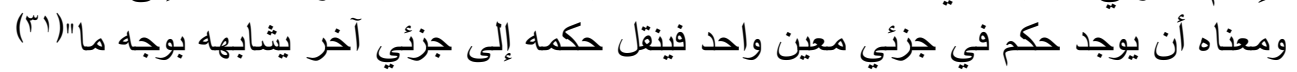
واستخدم الإمام البغدادي قياس الفي الغائب على على الثاهد:

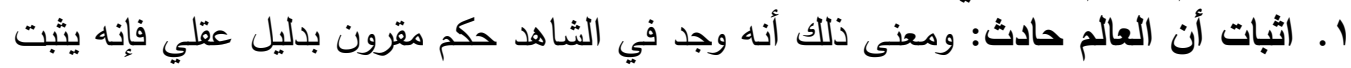

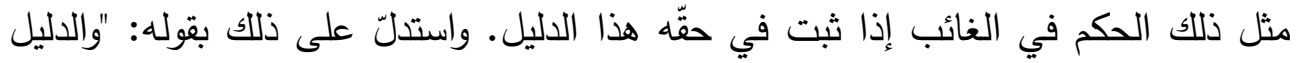

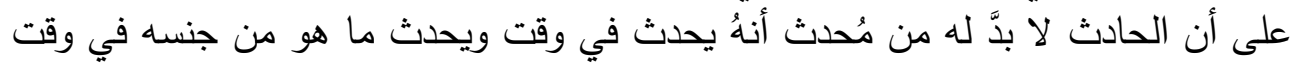

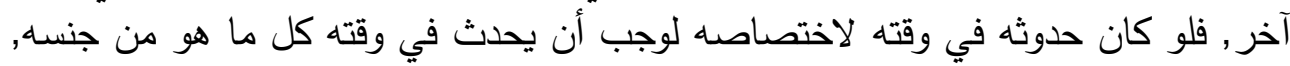

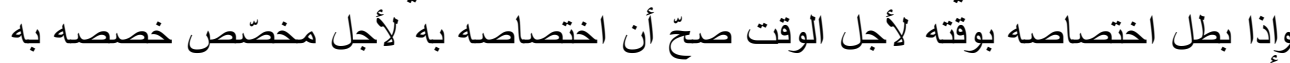

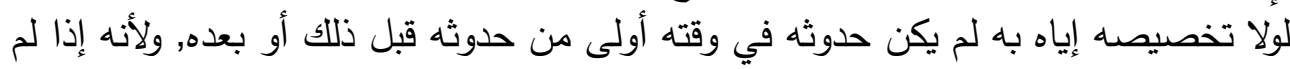

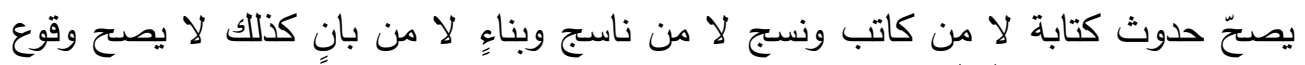

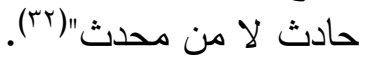
r. خلق الأفعال:يرى الإمام البغدادي أن جميع أفعال البشر تقع تحت حكم الله سبحانه وتعالى

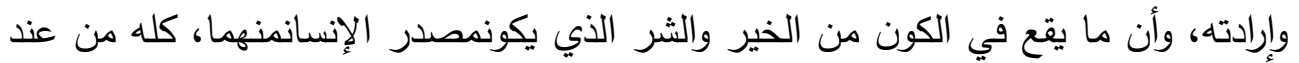

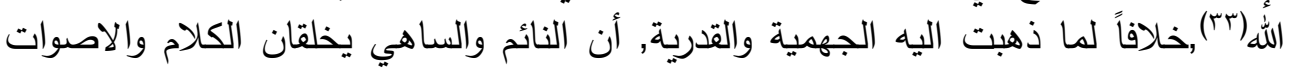
والحركات والآلام التي لا لهات علم لهم بها.

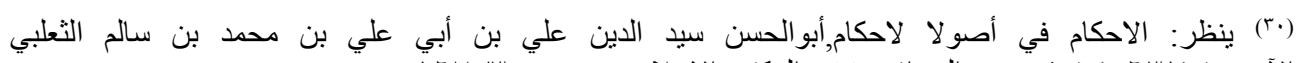

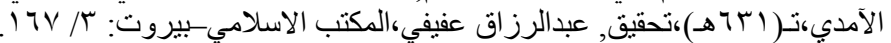

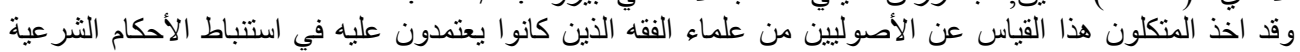

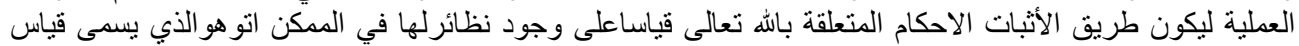

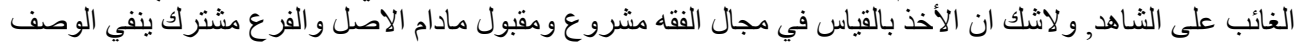

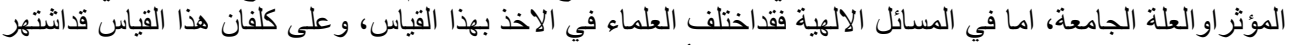

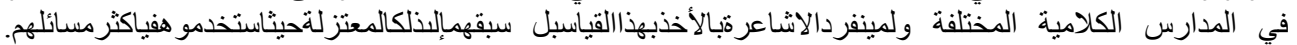

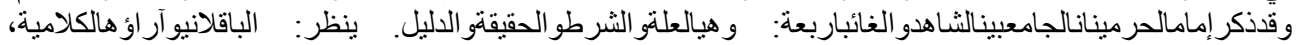

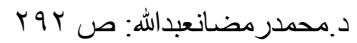
(بار)معيار العلم في فن المنطق, أبو حامد محمد بن محمد الغزالي الطوسي (ت: 0.0هـ) تحقيق: الدكتور سليمان دنيا:

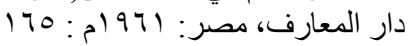

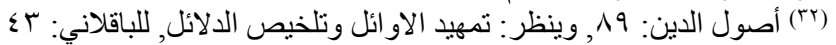

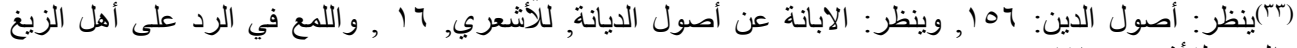

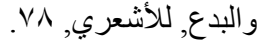

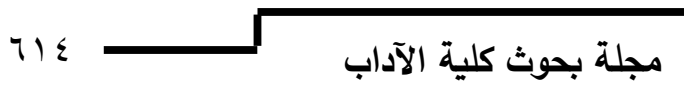


المنهج الاستدلالي العقلي عند الإمام عبد القاهر البغدادي

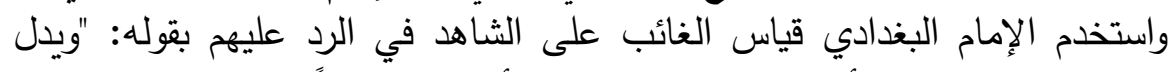

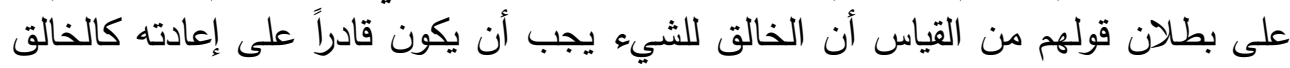

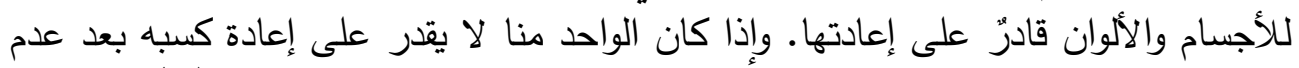

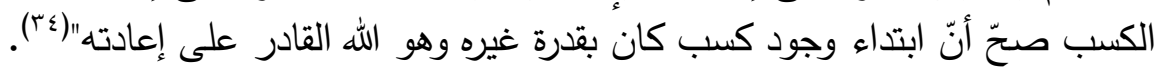

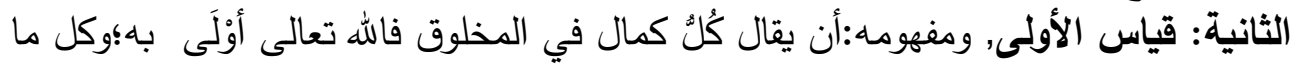

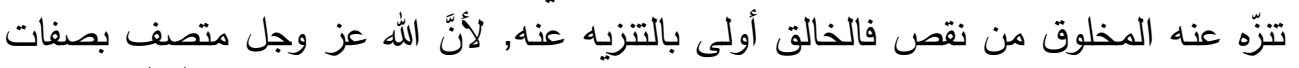

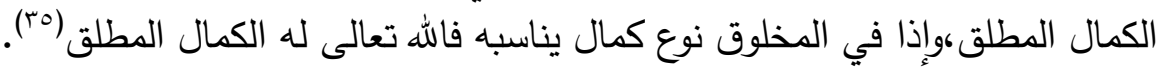

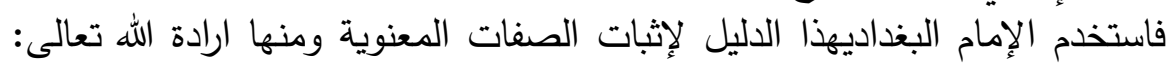

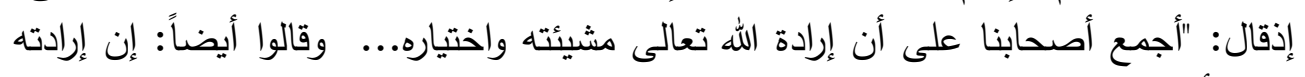

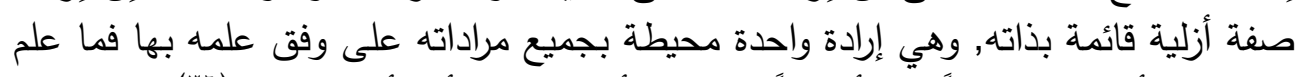

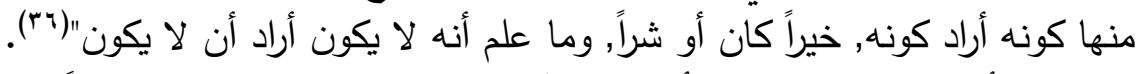

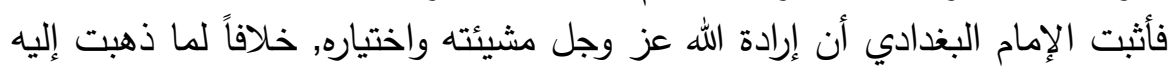

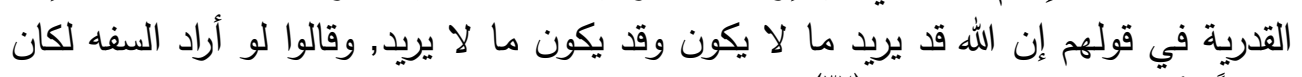

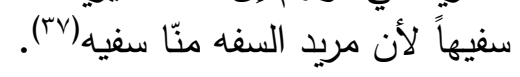
وردَّالإمام البغدادي عليهه: أن مريد الطاعة منا مطيع ولا يجب أن أن يكون الله مطيعاً

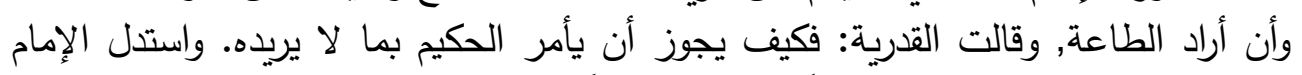

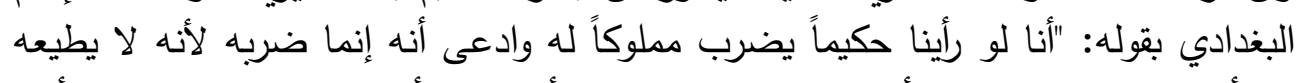

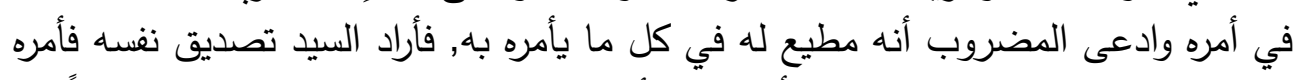

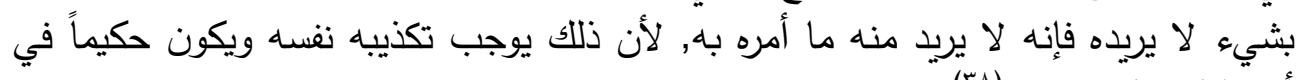

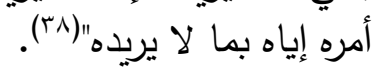

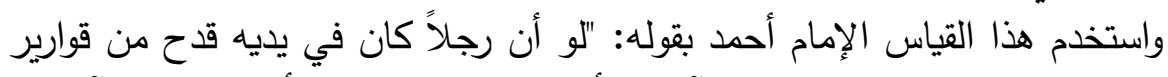

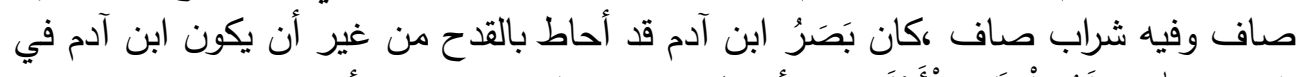

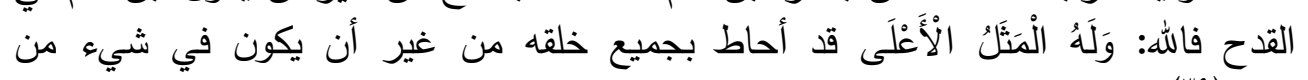
خلقه" (ra).

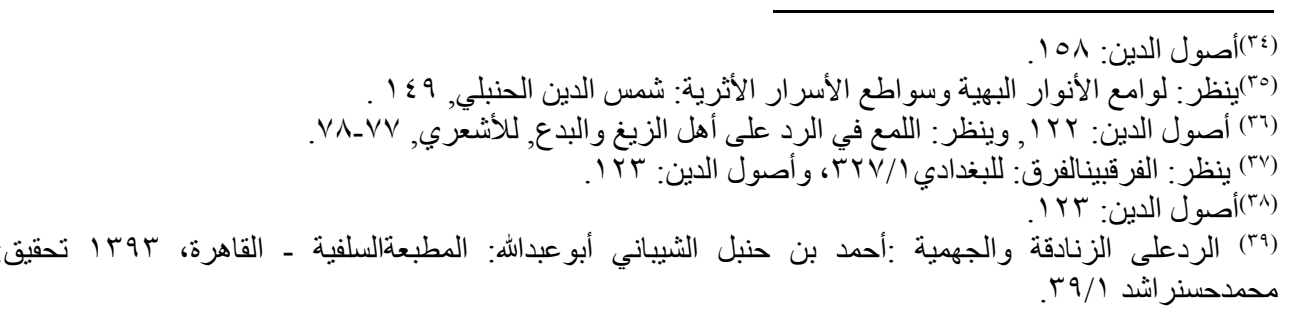


أ.م.د. هادي عبيد حسن /أ. عصام محمود جاسم المحدي منهجه في السبر والتققيم

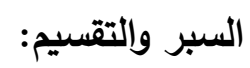

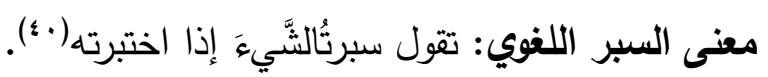

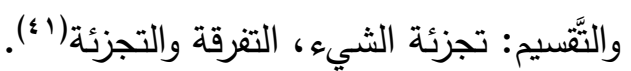
معنى السَّبر والتيَّقسيم اصطلاحاً:

والسَّبر: هو اختبار الوصف، هل يصلح للعلّيّة أم لا, والتَّسيم: هو حصر الأوصاف الموجودة في الأصل التي يظنّ صلاحيتها للعلّة ابتداءً، فيقال: العلّة إمَّا كذا وإمَّا كذا(r)

ثم أطلق مجموع هذين اللفظين في الاصطلاح على مسلك خاص من مسالك العلّة، وعرّفوه بأنَّه: "حصر الأوصاف التي توجد في الأصل "المقيس عليه"، والتي تصلح للعلّيّة في هلي بادئ الرأي، ثم اختبارها بإبطال ما لا يصلح بطريقة، فيتعيّن الباقي للعلّيّة"("זء).

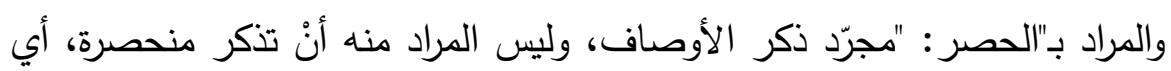
مرددة بين النفي والإثبات ليشمل قسمي: التقسيم المنحصر والمنتشر "( ؛ ؛). وتسمية هذا المسلك بمجموع هذين الاسمين واضحة، إلاًّ أنَّ الموافق للترتيب الخارجي أنْ يقال: "التَّسيم والسَّبر"، بتقديم "التَّسيم" على "لآلَّبَّر"، لكنهم عكسوا الترتيب؛

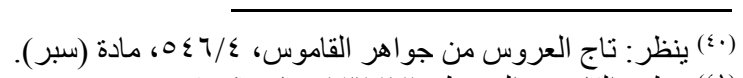

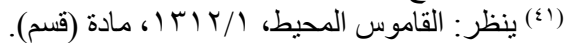

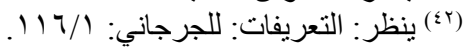

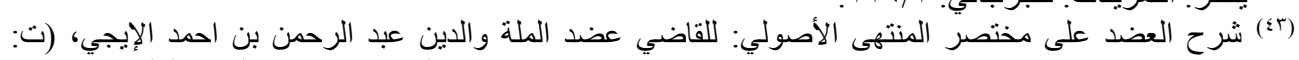

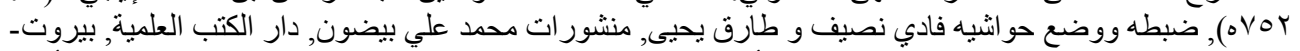

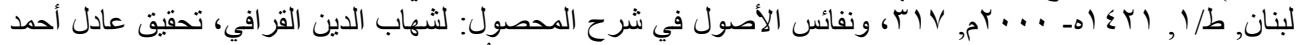

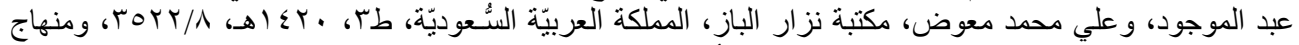

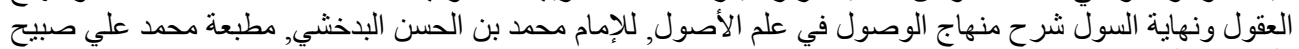

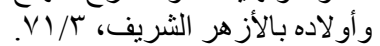
(؛ ؛ نبراس العقول في تحقيق القياس عند علماء الأصول, عيسى منون, المدرس في القسم العالي للجامع الأزهر, إدارة

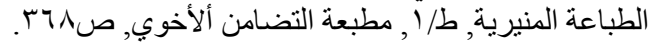


المنهج الاستدلالي العقلي عند الإمام عبد القاهر البغدادي

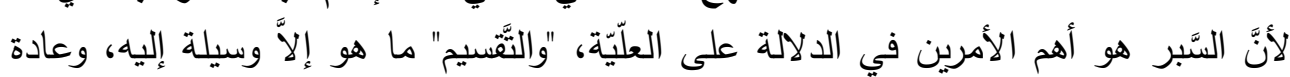

$$
\begin{aligned}
& \text { العرب تقديم الأهم في التعبير على غيره(ه ؛ الهان. } \\
& \text { وهذا الاليل يتركب من أصلين: }
\end{aligned}
$$

حصر أوصاف المحل ومعناه التقسيم, واختبار تلك الأوصاف المحصورة وإبطال ما هو

$$
\text { باطل منها لإبقاء ما هو صحيح (T)؛ }
$$

ومثاله: أن نحصر العدد بين الفردية والزوجية فنقول هذا العدد اما فرد أو زوج

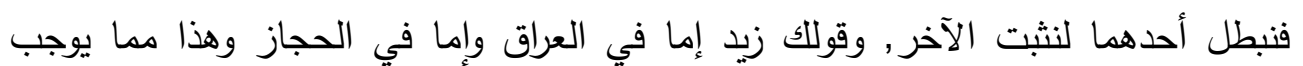

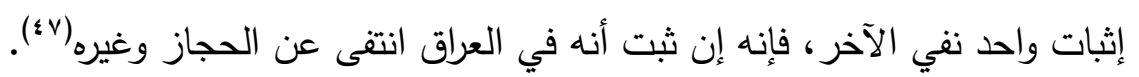

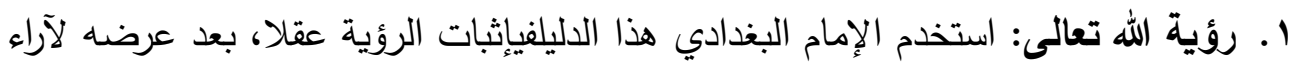
خصومه, فقال:" ودليلنا على رؤية الأعراض التمييز بالبصر بين الأسود والأبيض وبين المجتمع والمفترق, وفي هذا دليل على إدراك الألوان والأكوان بالبصر , وقول من زعم أن

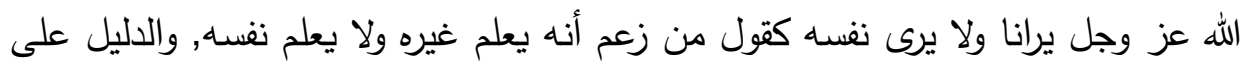

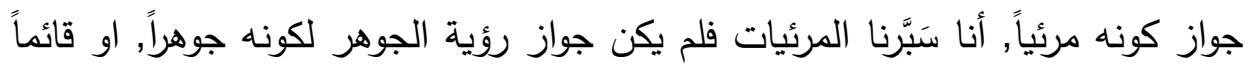
بنفسه, لأنّا نرى اللون وليس بجوهر ولا قائم بنفسه, ولم يكن جواز رؤية اللون لكونه لوناً

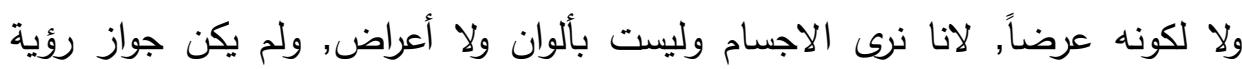
الثيء لكونه معلوماً أو مذكوراً, لأن ذلك يوجب جواز رؤية المعدوم, ولم يكن جواز رؤية ولهاب

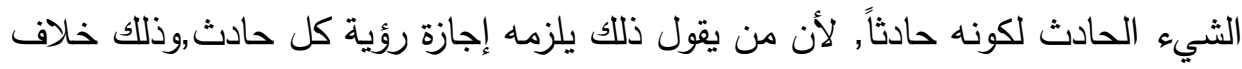
قول مخالفينا, وإذا بطلت هذه الأقسام لم يبقَ الا الوجود, صح جواز رؤية الثيء لوجوده فصح بذلك جواز رؤية كل موجود, و الله سبحانه وتعالى موجود فصح جواز رؤيته"(1؛).

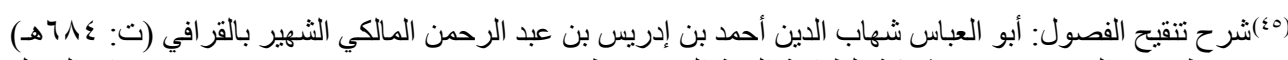

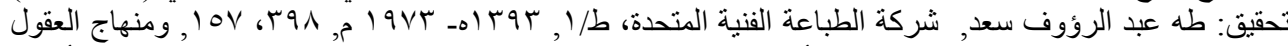

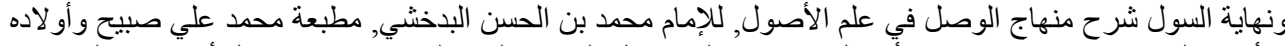

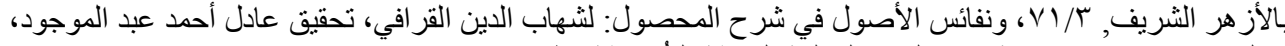

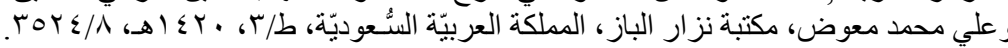

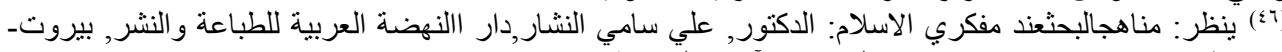

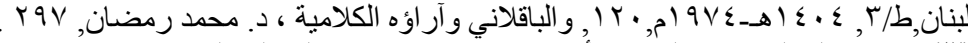

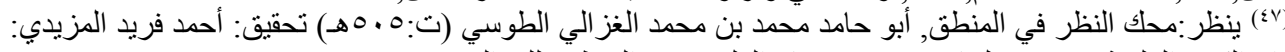

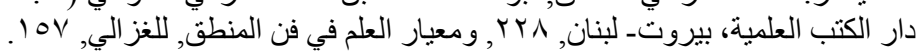

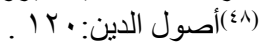


وقد سلك الإمام البغدادي في هذه المسألة طريق السَّبر والتتسيم وهي حصر الأوصاف التي تصلح للعلية في بادئ الرأي، ثم إبطال ما لا يصلح منها فيتعين الباقي في فئي

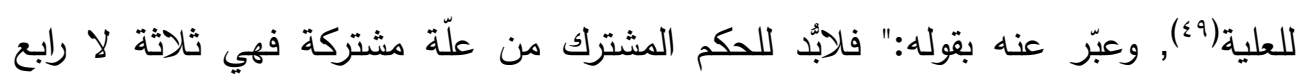

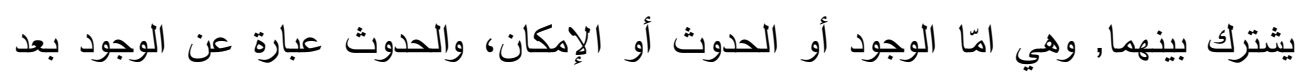

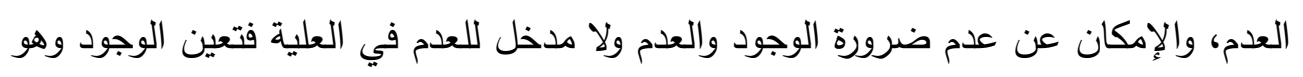
مشترك بين الصانع وغيره فيصح ان يرى من حيث تحقق علة الصحة وهي الوجود، و الله

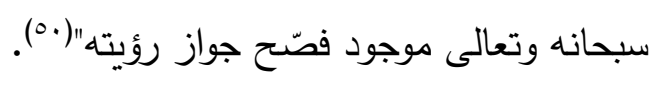

يقول أ.د. محمد رمضان (01)رحمه الله:" وقد حاول بعض البه الباحثين ردّ هذا الدليل إلى

القياس الشرطيّ المنفصل كما فعل الغزالي وغيرهُ من الأصوليين المتأخرين الذين سيطرت عليهم نزعة عامة تذهب إلى رد طرق البحث الأصولية إلى المنطق اليوناني, ولكني أرى أنَّ

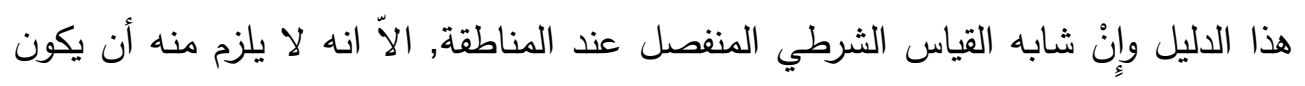

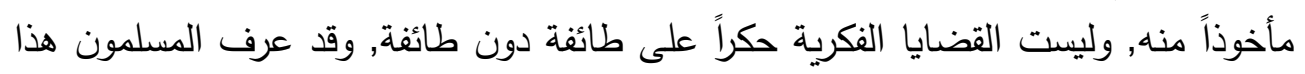

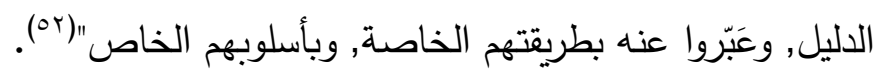
r. نفي الحِّد والنهاية عن الصانع: استخدم الإمام البغدادي هذا الدليل فقال:" لو كان الإله

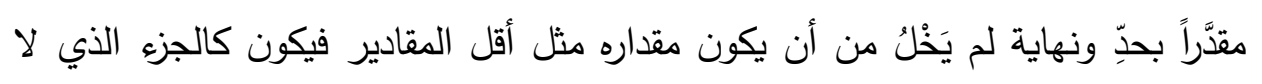
يتجزًا, أو يختّص ببعض المقادير فيتعارض فيه فيه المقادير فلا يكون بعضها أولى من من بعض إلا بمخصّص خصّه ببعضها, وإذا بطل هذان الوجهان صحّ أنه بلا حدّ ولا لِانِ

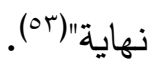

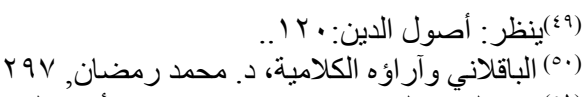

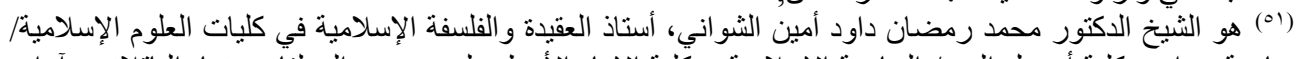

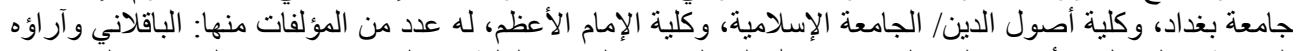

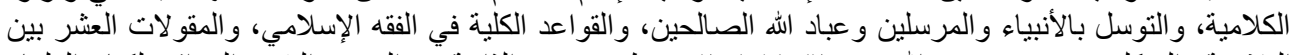

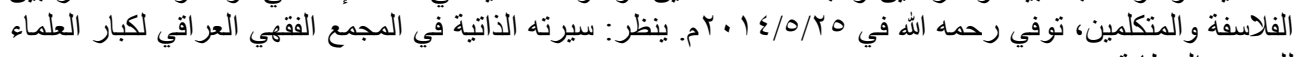
للاعوة و الخطابة.

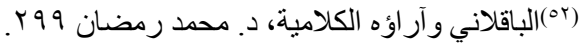
. (أصول ألدين: 


\section{المنهج الاستدلالي العقلي عند الإمام عبد القاهر البذادي}

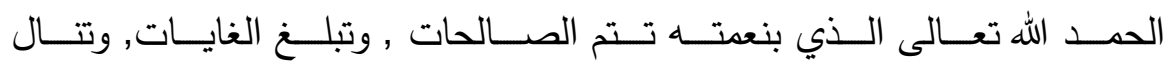

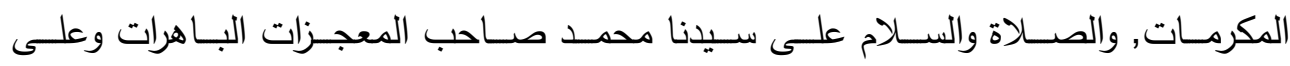

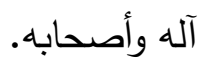

بعـد هــذه الجولــة الفكريـة ومنهجيـة الإمـام البغـدادي فـي مســالة الاســـلال العقلي من كتابه "أصول الدين" أبيّن أبرز تلكم النتائج:

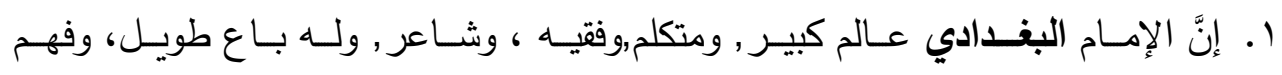

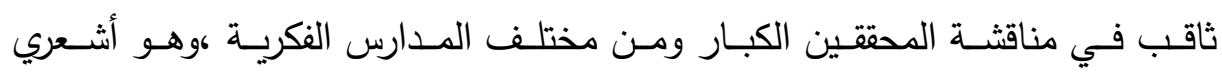

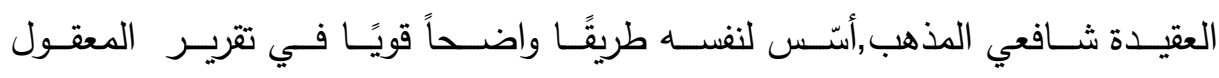
والمنقول.

r. الإمـام أبـو منصـور البغـدادي كـان مطّلعـاً على الآراء الكلاميـة التي كـان لهـا

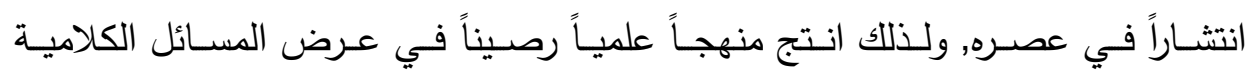

ومناقشتها لكونه يمتلك عقلية هندسية عالية

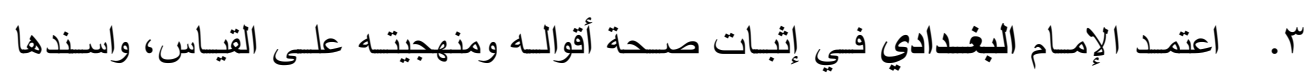

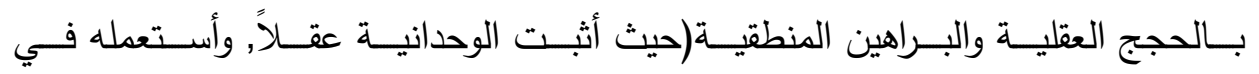

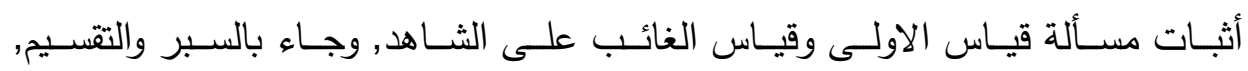

$$
\text { في مسألة الرؤية ونفي الحد عن الصانع • }
$$

وفي الختـام وقبـل الإمسـاك عـن الكـلام أرجـو أن يكـون عملي هـذا محسلَّ قبـول

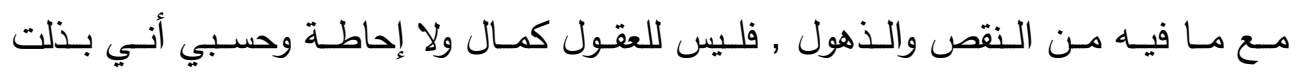

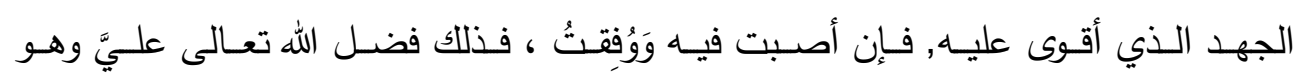

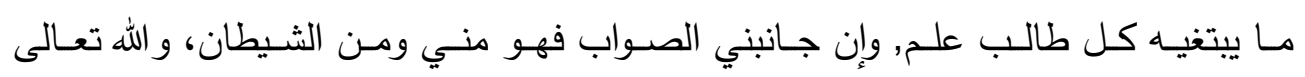

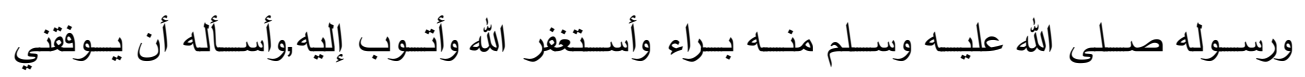

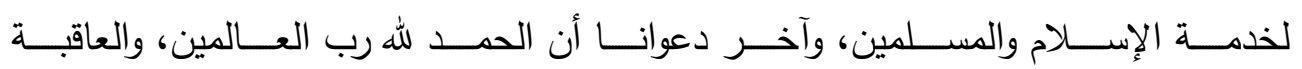
للمتقين، وصلى الله على سيدنا محمد وعلى آله وصحبه أجمعين. 


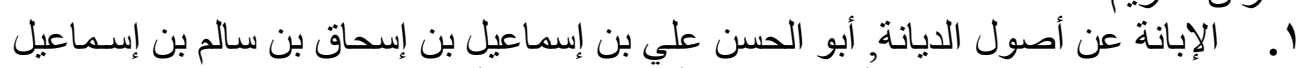

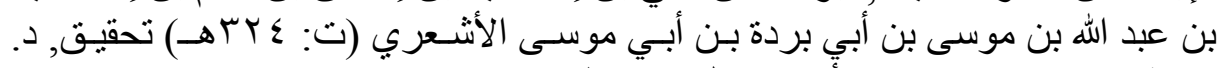

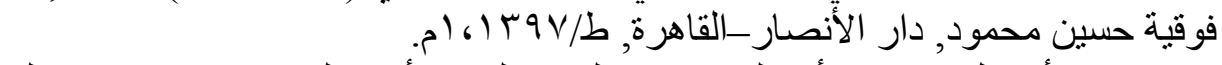

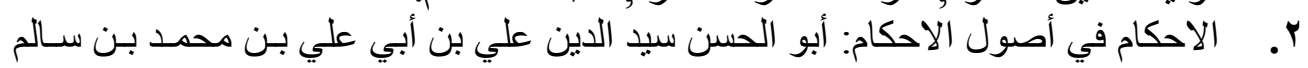

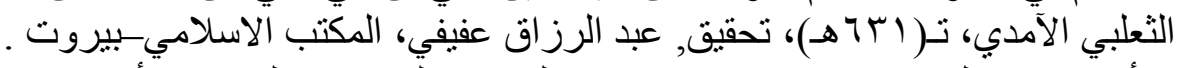

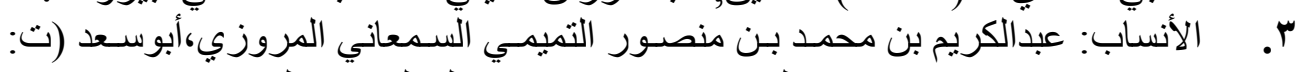

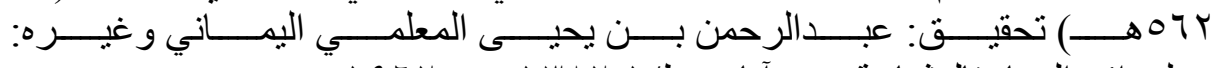

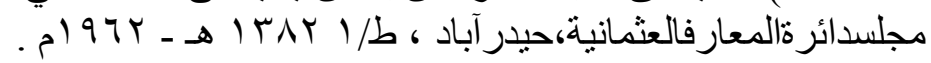

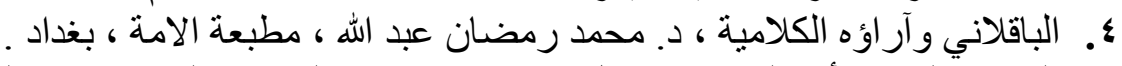

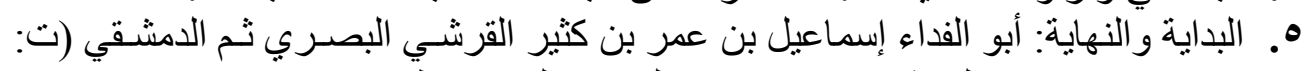

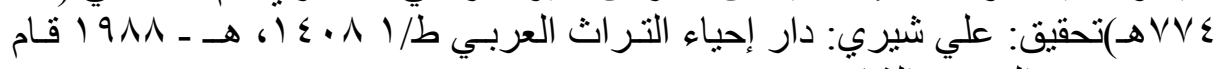

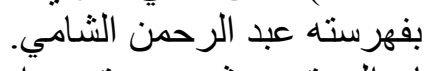

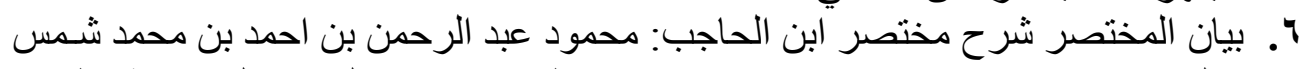

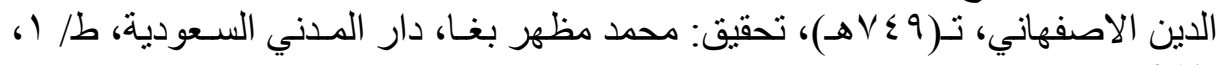

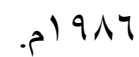

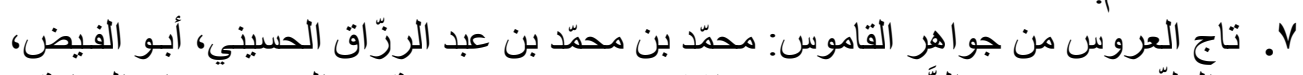

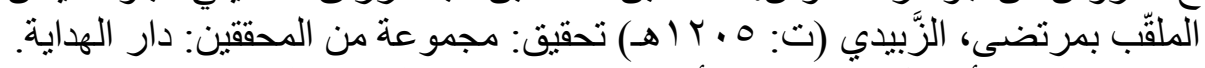

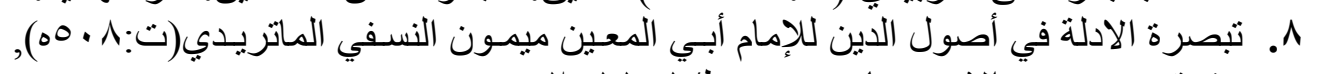

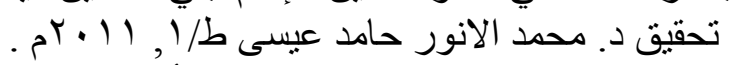

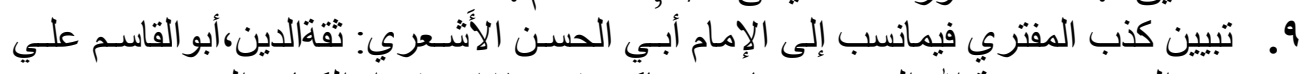

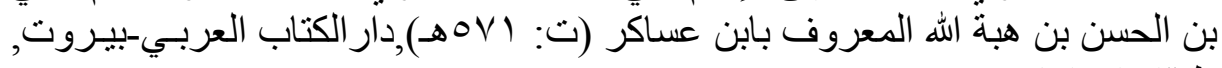

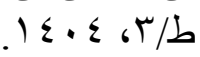

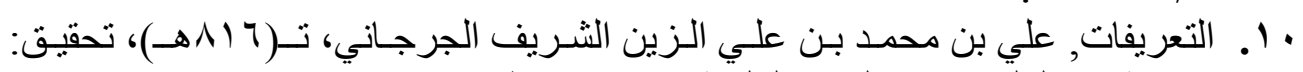

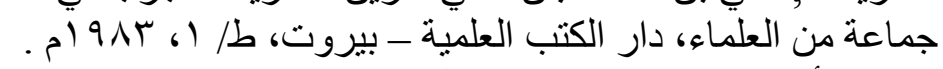

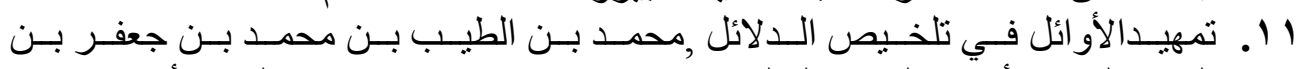

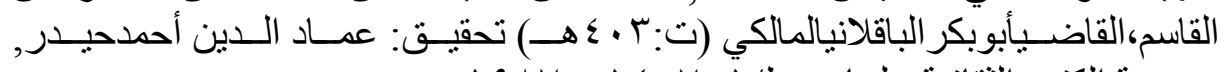

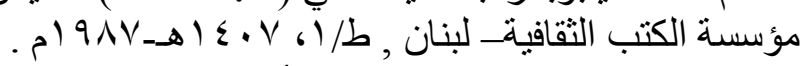

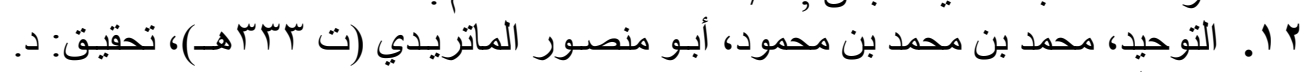
فتح الله خليف، دار الجامعات المصرية ــ الإسكندرية.

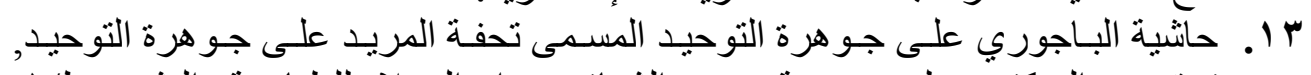

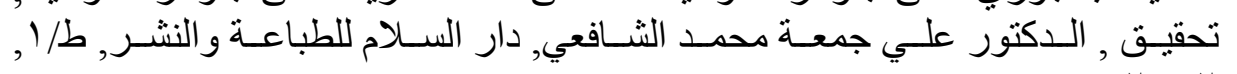

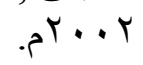


المنهج الاستدلالي العقلي عند الإمام عبد القاهر البغدادي

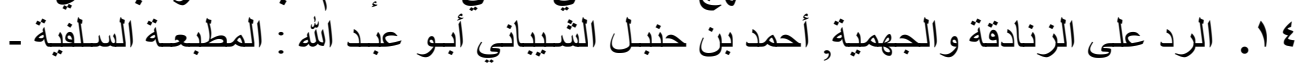

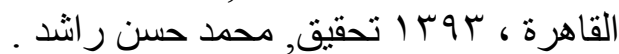

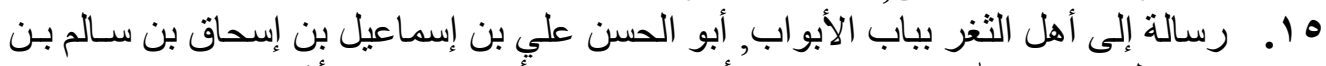

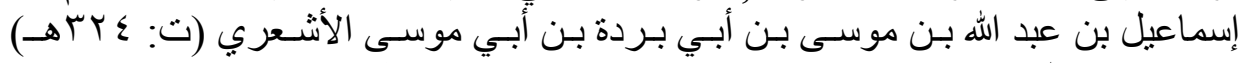

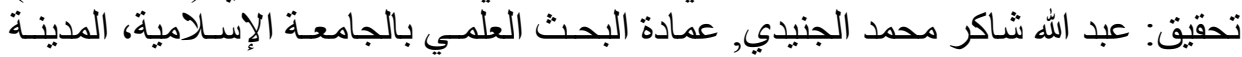

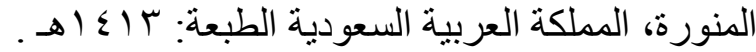

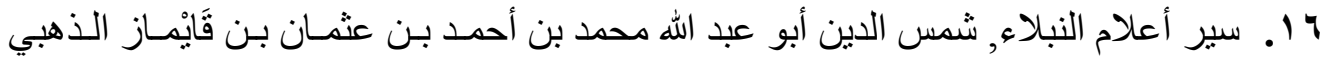

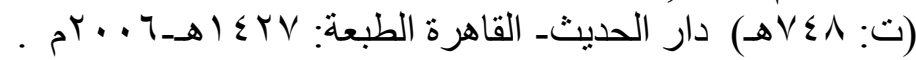

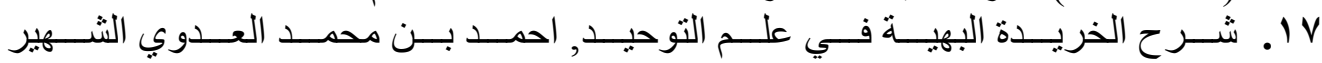

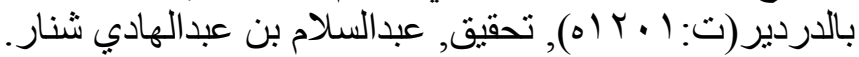

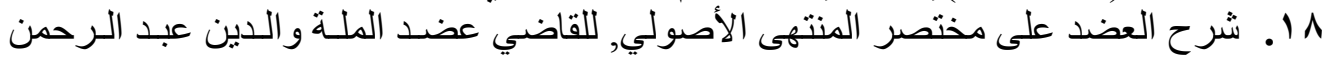

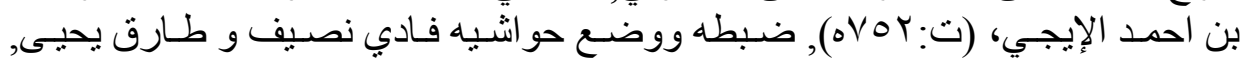

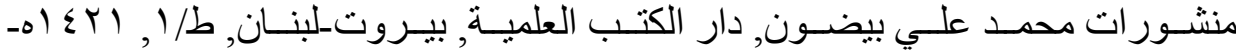

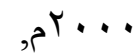

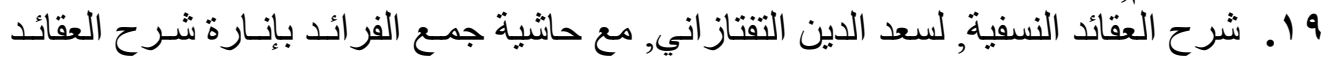

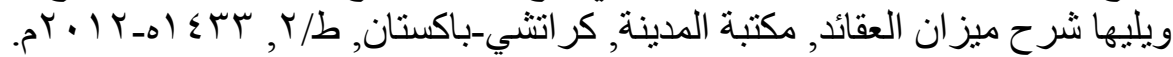

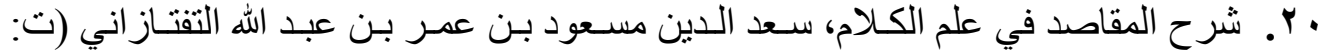

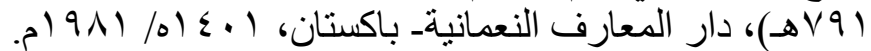

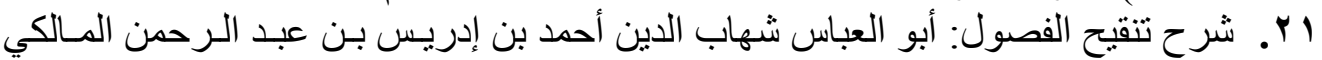

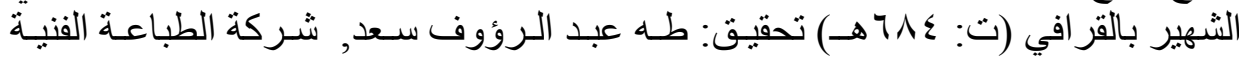

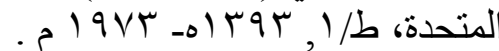

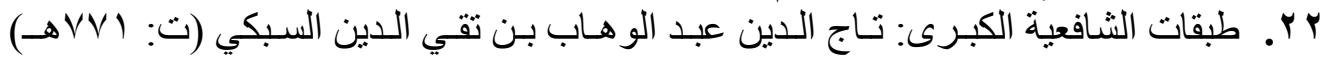

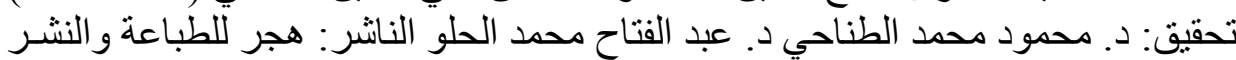

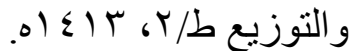

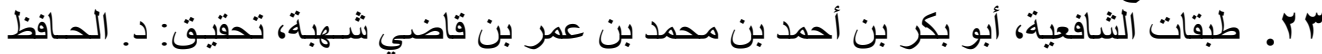

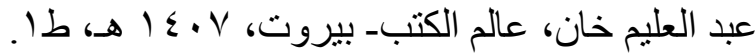

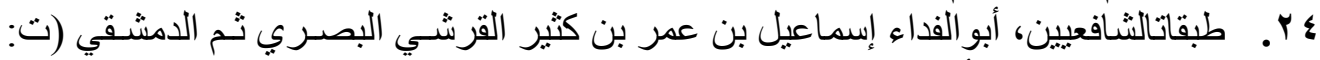

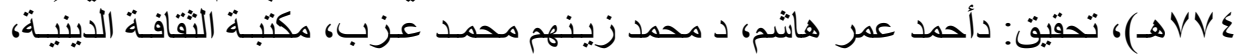

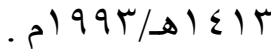

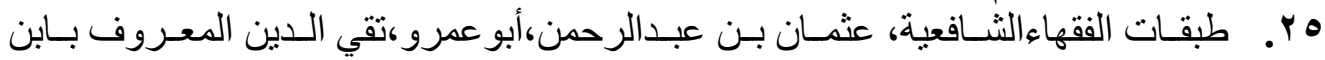

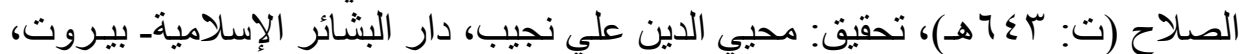
. مال

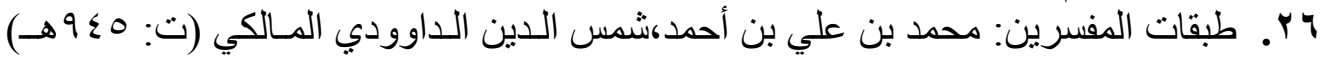

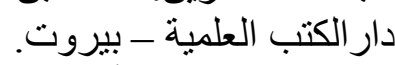
YV

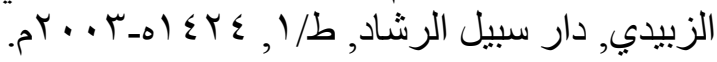




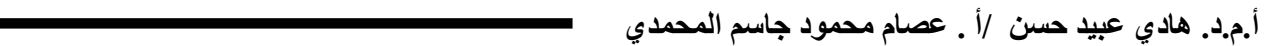

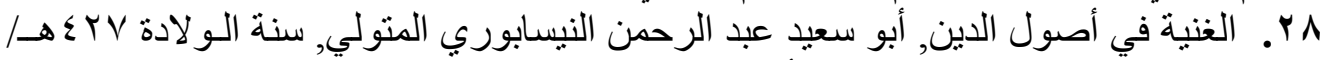

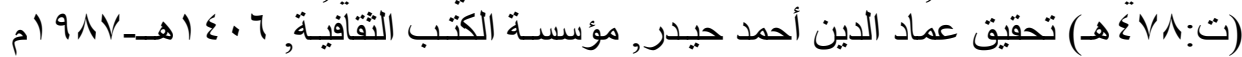

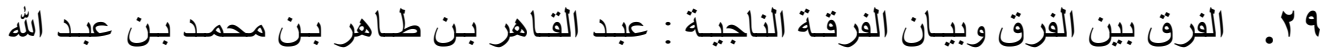

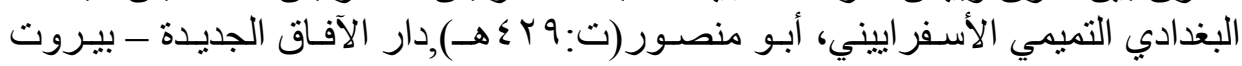

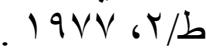

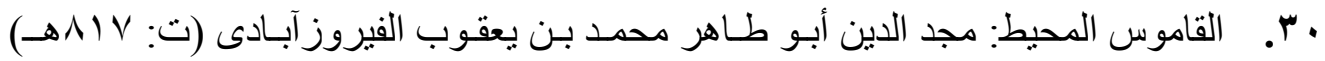

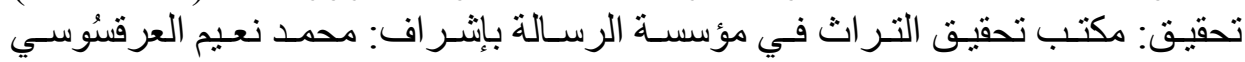

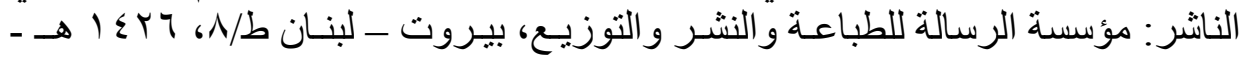
.

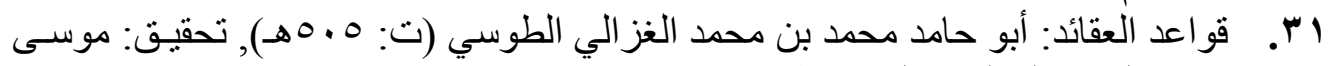

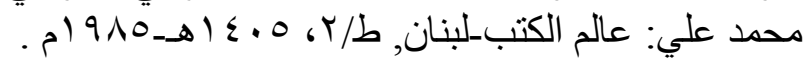

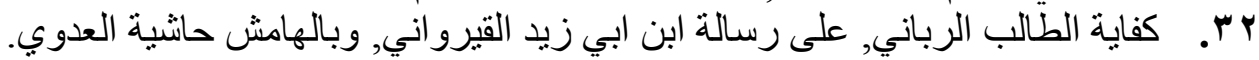

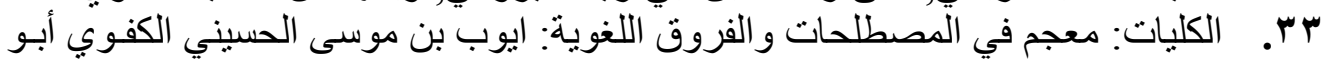

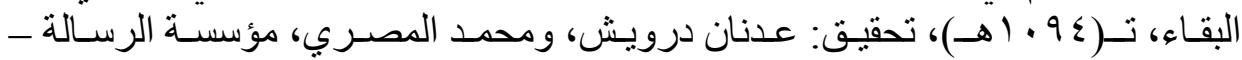

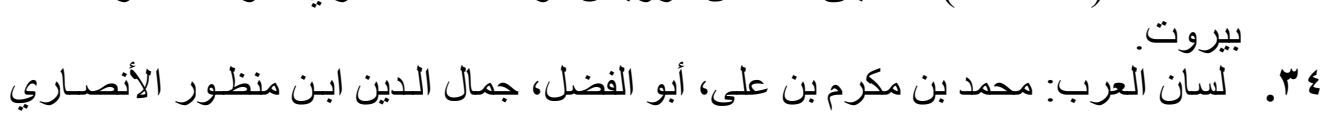

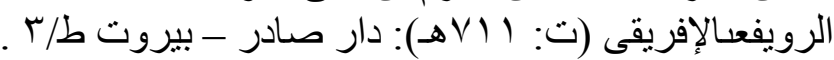

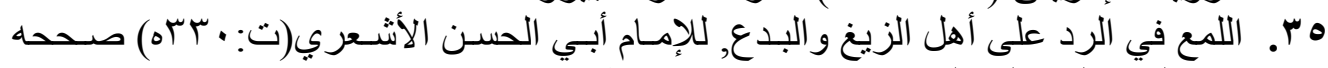

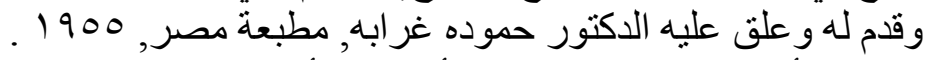

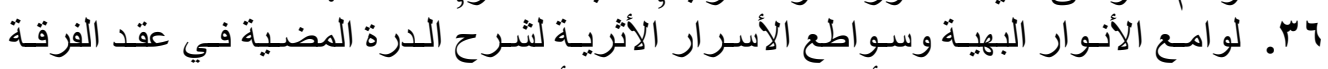

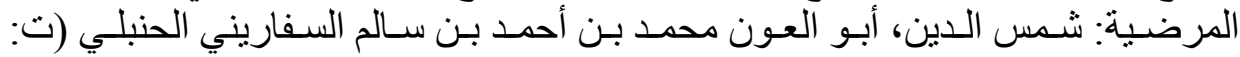

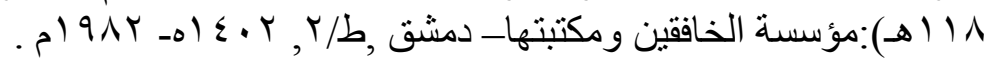
ع rv

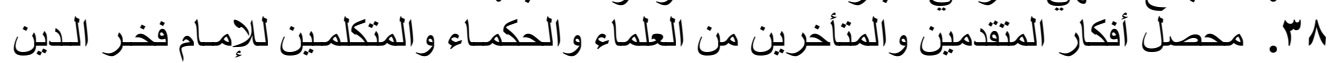

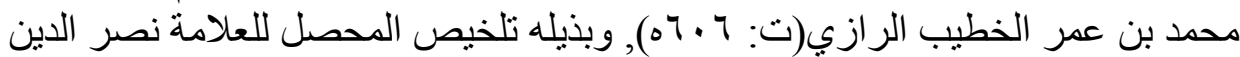

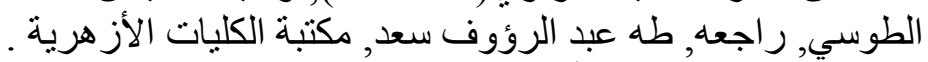

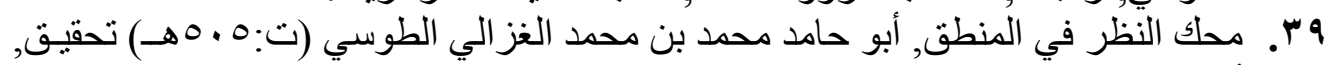

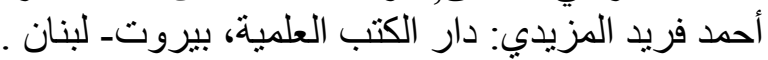

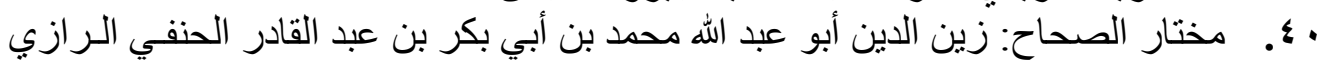

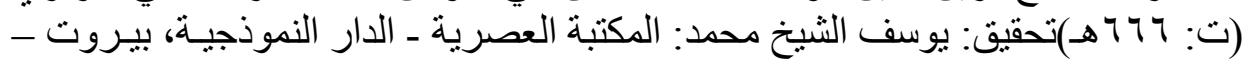

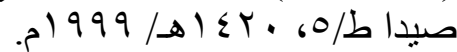

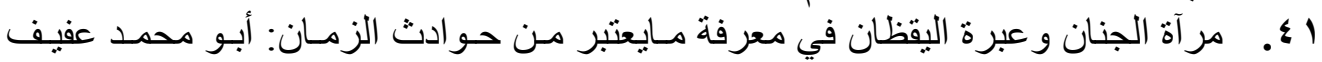

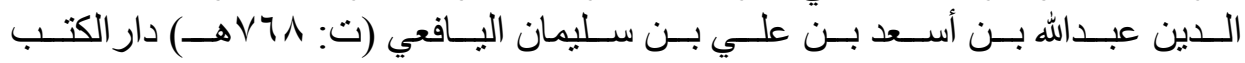

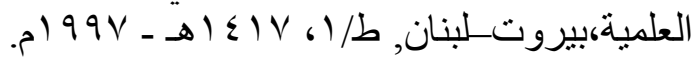

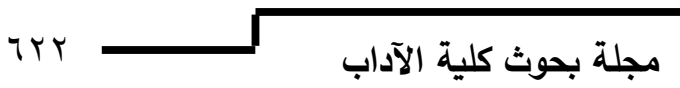


المنهج الاستدلالي العقلي عند الإمام عبد القاهر البغدادي

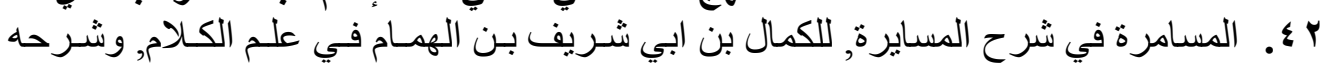

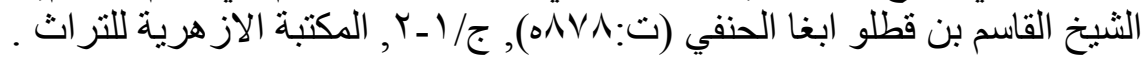

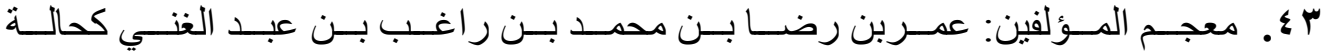

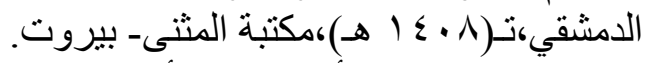

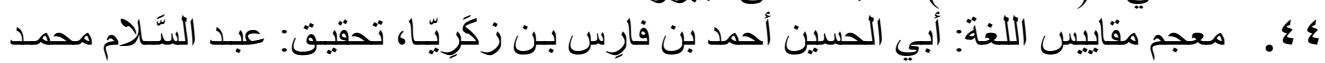

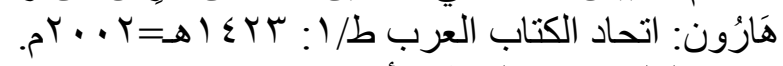

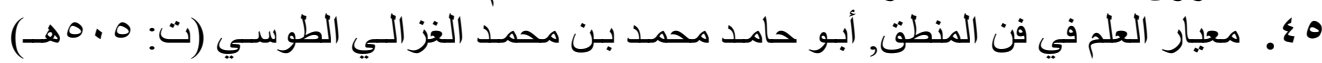

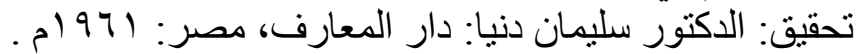

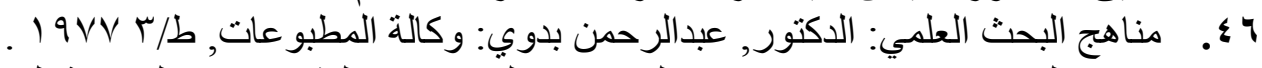

\& V

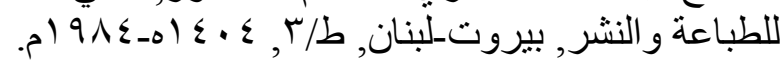

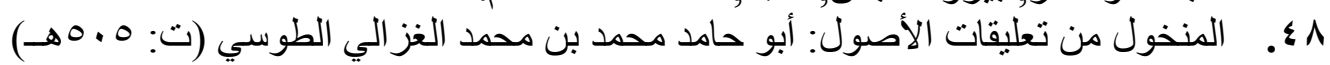

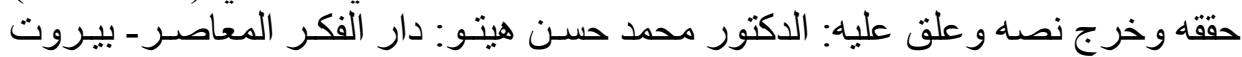

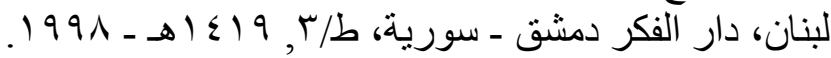

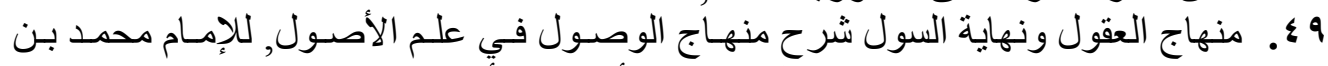

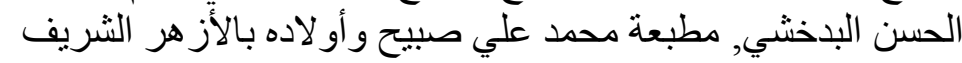

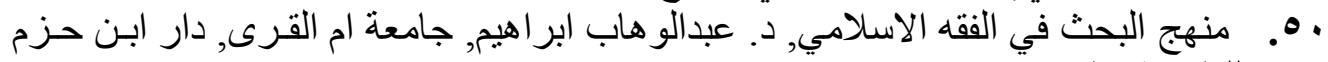

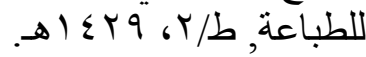

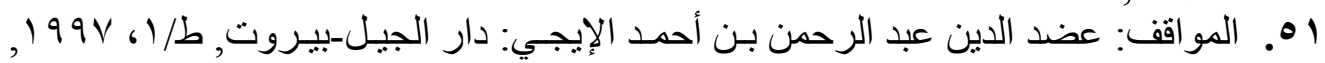
تحقيق: د.عبد الرحمن عميرة .

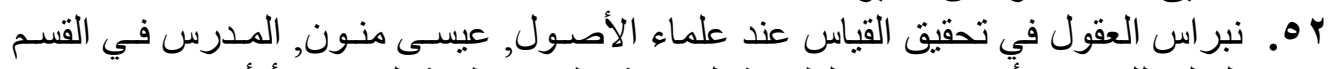

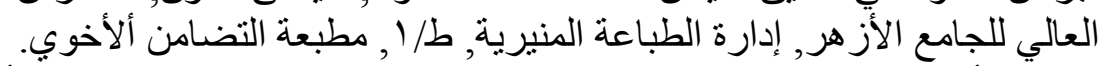

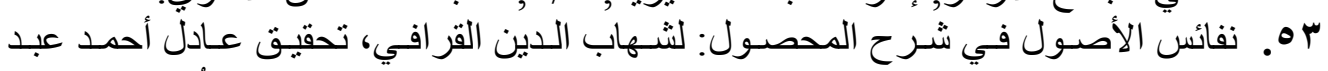

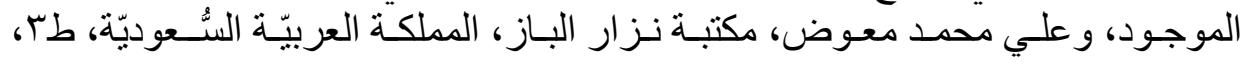
(هـ.

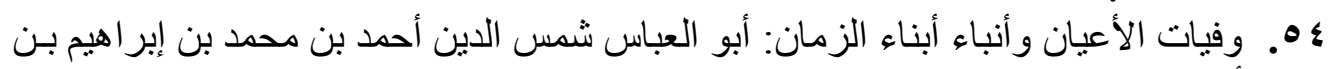

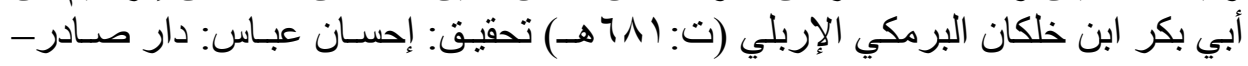




\begin{abstract}
After this intellectual tour in the methodology of Imam al-Baghdadi in the issue of mental reasoning from his book "Origins of the religion" I can show the most prominentresults:

Imam AL-Baghdadi is a great scholar and a speaker, and he was Ash'ari'i in his creed as assets and Shafi'i of the doctrine as branches. He established a clear approach in the report of the movable and the reasonable, and his book "Origins of the religion" which is consider as an encyclopedia to identify and explain the sectarian teams andthe opinions of its owners, where he addressed the various scholars' opinions of the controversial issues that he briefly addressed.

His style is clear and accurate in the presentation of the doctrinal issues, Imam AL-Baghdadi was an important reference that every student should be aware of it, because he made this book in fifteen originally around the sectarian matters, and having a mentality in the debate to prove what he proposes through measurement, and he supported that by rational arguments and logical evidence been proven .
\end{abstract}

\title{
The researcher
}

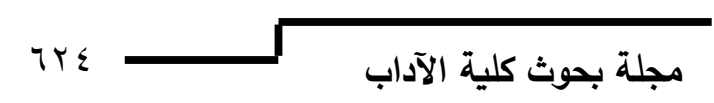

